\title{
User Manual for the Hanford Energy Conservation Project Data Base
}

\author{
K. K. Humphreys \\ L. L. Fassbender \\ S. A. Weakley
}

September 1987

Prepared for

the U.S. Department of Energy

under Contract DE-AC06-76RLO 1830

Pacific Northwest Laboratory

Operated for the U.S. Department of Energy

by Battelle Memorial Institute 


\title{
DISCLAIMER
}

This report was prepared as an account of work sponsored by an agency of the United States Government. Neither the United States Government nor any agency thereof, nor Battelle Memorial Institute, nor any of their employees, makes any warranty, expressed or implied, or assumes any legal liability or responsibility for the accuracy, completeness, or usefulness of any information, apparatus, product, or process disclosed, or represents that its use would not infringe privately owned rights. Reference herein to any specific commercial product, process, or service by trade name, trademark, manufacturer, or otherwise, does not necessarily constitute or imply its endorsement, recommendation, or favoring by the United States Government of any agency thereof, or Battelle Memorial Institute. The views and opinions of authors expressed herein do not necessarly state or reflect those of the United States Government or any agency thereof, or Battelle Memorial Institute.

\author{
PACIFIC NORTHWEST LABORATORY \\ operated by \\ BATTELLE MEMORIAL INSTITUTE \\ for the \\ UNITED STATES DEPARTMENT OF ENERGY \\ under Contract DE-AC06-76RLO 1830
}

\author{
Printed in the United States of America \\ Available from \\ National Technical Information Service \\ United States Department of Commerce \\ 5285 Port Royal Road \\ Springfield, Virginia 22161 \\ NTIS Price Codes \\ Microfiche A01 \\ Printed Copy
}

$\begin{array}{lr}\text { Pages } & \begin{array}{r}\text { Price } \\ \text { Codes }\end{array} \\ 001-025 & \text { A02 } \\ 026-050 & \text { A03 } \\ 051-075 & \text { A04 } \\ 076-100 & \text { A05 } \\ 101-125 & \text { A06 } \\ 126-150 & \text { A07 } \\ 151-175 & \text { A08 } \\ 176-200 & \text { A09 } \\ 201-225 & \text { A010 } \\ 226-250 & \text { A011 } \\ 251-275 & \text { A012 } \\ 276-300 & \text { A013 }\end{array}$




\section{3679000572109}

PNL -6318

UC-95

User Manual for The Hanford Energy Conservation Project Data Base

K. K. Humphreys

L. L. Fassbender

S. A. Weakley

September 1987

Prepared for the U.S. Department of Energy under Contract DE-AC06-76RLO 1830

Pacific Northwest Laboratory

Richland, Washington 99352 



\section{PREFACE}

The Hanford Energy Conservation Project (HECP) was developed as a mechanism for incorporating state-of-the-art conservation technologies and knowledge into Hanford projects and for determining research and development (R\&D) opportunities involving new construction projects or modifications of existing facilities. The basic elements of the program include (1) the identification of energy-conservation opportunities in existing or planned projects, (2) the integration of R\&D technology into site projects, and (3) energy-conservation information exchange among al1 Hanford contractors.

The Hanford Energy Conservation Data Base was developed as a management tool for monitoring the progress of proposed, on-going, and completed projects managed by the HECP. This user manual was designed to be used in tandem with the user friendly screen menus and prompts by the data base management option. The data base is intended for use mainly by HECP management and not for widespread distribution; therefore, the user manual is designed for an adept computer-user having familiarity with the HEC project. 
The Hanford Energy Conservation (HEC) Project Data Base developed by the

- Pacific Northwest Laboratory for the U.S. Department of Energy's Richland Operations Office, provides a centralized storehouse of information on planned and ongoing projects which are part of the HEC project. The data base will enable quick analysis of the project portfolio. The data base uses dBase III Plus ${ }^{(a)}$ on an IBM PC ${ }^{(b)}$. Over 40 data items are stored for each project. A menu-driven applications program was developed as an alternative to using standard dBase III Plus commands. The menu-driven program prompts the user to add data, edit data, perform on-screen searches of the data base, sort the data base by any variable or combination of variables, or generate hard-copy reports of the stored data.

(a) dBase III is a trademark of Ashton-Tate, Culver City, California.

(b) IBM PC is a trademark of International Business Machines Corporation, Boca Raton, Florida. 



\section{ACKNOWLEDGMENTS}

The authors gratefully acknowledge the technical review of this document

- and software by Mr. Harlan Huber. His comments enabled us to develop the data base into an extremely useful management tool. We would also like to thank Rachelle Gibby for typing and editing. 



\section{CONTENTS}

PREFACE ................................ . . . . . . .

SUMMARY . . . . . . . . . . . . . . . . . . . . . . V

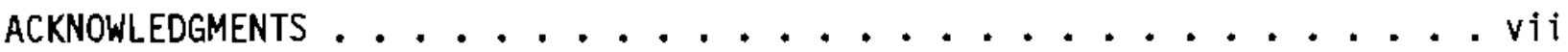

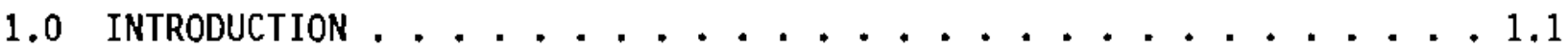

2.0 OVERVIEW OF THE HEC PROJeCt DATA BASE. . . . . . . . . . . . 2.1

3.0 GETTING STARTED. . . . . . . . . . . . . . . . 3.1

3.1 BASIC HARDWARE AND SOFTWARE REQUIREMENTS. . . . . . . . 3.1

3.2 DOS CONFIGURATION . . . . . . . . . . . . . . 3.1

3.3 LOADING dBASE III PLUS. . . . . . . . . . . 3.2

3.4 ACCESSING THE HEC PROJECT DATA BASE . . . . . . . . . . 3.2

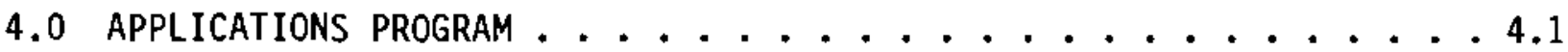

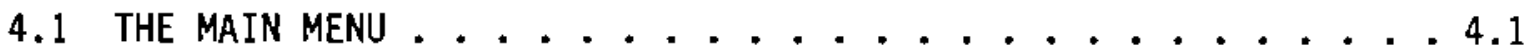

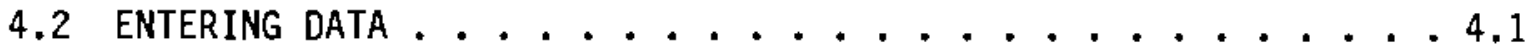

4.2.1 Entering Character and Numeric Data. . . . . . . 4.3

4.2.2 Entering the Project Description, Project
Justification, and Project Schedule. . . . . . . 4.4

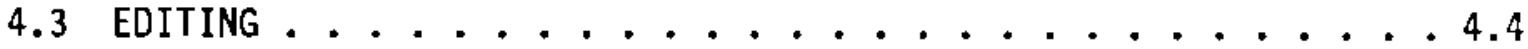

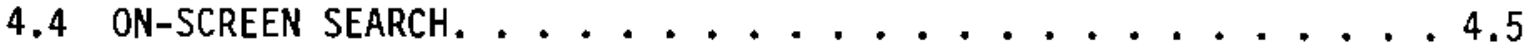

4.4.1 Title Search.................. 4.5

4.4.2 Keyword Search .................. 4.5

4.4.3 Boolean Search ................. . . 4.6

4.5 PRINTING REPORTS. . . . . . . . . . . . . 4.8

4.6 HELP. . . . . . . . . . . . . . . . . . . 4.9

4.7 EXITING THE APPLICATIONS PROGRAM. . . . . . . . . . 4.9 


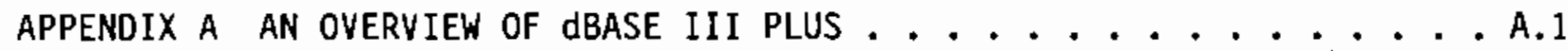
APPENDIX B PROGRAM LISTING .................... B. APPENDIX C TROUBLE-SHOOTING GUIDE. . . . . . . . . . . . . . . 


\subsection{INTRODUCTION}

The Hanford Energy Conservation (HEC) Project Data Base is a microcomputer data base with menu-driven software that manages project information for the HEC project. It was developed for use with the dBase III Plus data base management system. The HEC data base can be accessed in two ways:

1. Menu-driven software written to access the data base enables the beginning user to select options from displayed menus in order to perform various data management tasks.

2. Standard dBase III Plus commands enable the experienced user to perform the full spectrum of data management tasks available with the dBase III Plus data base management system.

The HEC data base consists of a series of records in interconnected data files, each of which contains 48 fields of information on projects under the Hanford Energy Conservation Project.

The purpose of this User Manual is to describe the features of the HEC project data base and illustrate how to use them. It is intended as a companion to dBase III Plus documentation, not as a replacement. An overview of what is included in the data base is presented in Section 2.0. Section 3.0 tells the user how to get started using the HEC project data base. Use of the menu-driven applications program is discussed in Section 4.0. Appendix A presents an overview of the characteristics and capabilities of dBase III Plus. The program files of the HEC project data base are defined and listed in Appendix B. Appendix $C$ gives trouble-shooting information in the event a data base error occurs. 



\subsection{OVERVIEW OF THE HEC PROJECT DATA BASE}

PNL developed this computerized data base as a key part of the Hanford Energy Conservation Project. The data base was created to provide a centralized storehouse of information on all potential and ongoing energyconservation projects at the Hanford Site. The addition of new projects to the data base as they are developed and the updating of project information already contained in the data base is critical to the usefulness of the data base. The data base system includes the following items for each project:

- Project Title

- Project Description

- Project Justification

- Project Schedule

- Current Status

- Project Manager

- Research Contact

- Other Contacts

- Project Location

- Project Cost

- Project Spending

- Electricity Savings

- Thermal Energy Savings

- Non-Energy Benefits

The HEC data base consists of three data base files:

1. HPLAN.DBF: The main HEC data base. The file HPLT.NDX is an index file created by indexing HPLAN.DBF on the project title (PRJTITLE).

2. HPLMEM.DBF: This data base contains a list of three memo fields for the project description, justification, and schedule. The file HPLMEM.DBT is an auxiliary data base containing the memo data typed into the three memo fields listed in the HPLMEM data base.

3. HPLKEY.DBF: The data base containing keywords

Each record in any one data base file is related to one record in the other two database files through the two key fields common to all three data bases: PRJTITLE and PRJNO. 



\subsection{GETTING STARTED}

This section first defines the basic hardware and software required to use the HEC project data base. Next, the steps necessary to properly configure the disk operating system are explained, followed by the procedure for loading the dBase III Plus program. Finally, the procedure used to access the HEC project data base system is described.

\subsection{BASIC HARDWARE AND SOFTWARE REQUIREMENTS}

Before beginning, check that the following basic hardware and software requirements are met:

1. The IBM-PC or compatible microcomputer has two floppy disk drives or one floppy drive and a hard disk.

2. The microcomputer has at least $512 \mathrm{~K}$ of internal memory

3. A copy of the DOS operating system software (PC DOS version 2.0 or higher or MS DOS version 2.1 or higher).

4. A copy of dBase III Plus software.

\subsection{DOS CONFIGURATION}

In order for dBase III Plus to run properly, the file CONFIG.SYS must be on the DOS boot disk. This file must be configured to accommodate the maximum number of data base files and data buffers needed, which is recommended as 20 and 15, respectfully. To see if the CONFIG.SYS file is on the DOS boot disk, enter the command "TYPE CONFIG.SYS". If the CONFIG.SYS file is present, you can use a text editor, such as EDLIN, WORD STAR, or WORDPERFECT, to add the following lines to it or modify the default settings, if necessary:

FILES $=20$

BUFFERS $=15$

If the CONFIG.SYS file is not present, it can be created from the console using the steps described below. Press the RETURN key after each command is entered.

1. Check that the DOS boot disk is in drive $A$ and that the 'A' prompt appears on the screen. 
2. Type: COPY CON: CONFIG.SYS

3. Type: FILES $=20$

4. Type: BUFFERS $=15$

5. Press the $F 6$ function key, release it, and then press the RETURN key to create and save the CONFIG.SYS file on your DOS boot disk.

Examine the CONFIG.SYS file to verify the entries. If a mistake was made, re-create the file by repeating the above five steps. Once the CONFIG.SYS file is created and has been saved on the DOS boot disk, the file does not need to be recreated when you reuse dBase III Plus.

If the DOS boot disk already had the proper version of the CONFIG.SYS file, dBase III Plus can be loaded. If it did not and the proper version of CONFIG.SYS was just placed on the DOS boot disk, the computer must be rebooted by pressing the CTRL, ALT, and DEL keys simultaneously.

\subsection{LOADING DBASE III PLUS}

If you have a two-disk dBase III Plus program, the two disks are labeled "System Disk \# 1" and "System Disk \#2". In order to load dBase III Plus, perform the following three steps:

1. Insert System Disk \# 1 into floppy drive A

2. Type DBASE and press the RETURN key

3. When prompted to do so, remove the System Disk \# 1 from drive A and insert the System Disk \#2 and press the RETURN key.

When dBase III Plus has been successfully started, a menu screen will be displayed in the upper left hand corner of the screen.

4. Press the ESC key

A '.' prompt will now be displayed on the screen with a status bar along the bottom of the screen. 


\subsection{ACCESSING THE HEC PROJECT DATA BASE}

To access the HEC project data base, insert the disk containing the HEC software package into drive $B$ and proceed in one of the following two ways. Option A

To activate the menu-driven software, type the following two commands and press the RETURN key after each one:

\section{SET DEFAULT TO B}

2. DO MENU

This will cause the menu program to load into internal memory from the disk in drive $B$ and display the Main Menu that allows the user to interface with the data base. If Option A is selected, character input responses to the menu prompts should be entered with uppercase letters.

Option B

To bypass the menu-driven software, type the following two commands and press the RETURN key after each one:

1. SET DEFAULT TO B

2. USE "file" (where "file" is the data base of interest). To access the main data base file in the HEC project data base, type: USE HPLAN and press the return key.

This allows the use of dBase III Plus commands to access and manipulate the data base. 



\subsection{APPLICATIONS PROGRAM}

An interactive, menu-driven program is provided to enter, edit, sort and report the data in the Hanford Energy Conservation Project Data Base. The applications program has a modular design. Subroutines are called and executed from the main program (MENU.PRG) as shown in Figure 4.1. These subroutines are of two types: command files (filename extension..PRG), and format files (filename extension. .FMT). Command files consist of sets of instructions in dBase III Plus programming language. Format files create custom screen formats for data entry or on-screen data display. Each of the modules shown in Figure 4.1 is discussed in detail below. In addition, Appendix B contains program listings for the command files and the screen format files.

\subsection{THE MAIN MENU}

The MENU program controls the execution of the appropriate subroutines based on the main applications selected from the on-screen menu. The four main applications that can be called from the MENU program are: (1) adding data for new projects to the data bases, (2) editing existing project data, (3) reporting project data, and (4) searching the data base for projects that meet user-specified criteria. In addition, a HELP program can be called which describes the functions of the major command programs. To execute the MENU program, follow the steps in Section 3.0, "Getting Started."

\subsection{ENTERING DATA}

The data entry program (ADD.PRG) allows the addition of information for a project that is not currently in the data base. The ADD program is executed when the ENTER DATA option is selected from the main menu. Data entry is accomplished through formatted screens that are called from the ADD program. These screens are stored as the files SCR1.FMT, SCR2.FMT, SCR3.FMT, SCR4.FMT, and SCR5.FMT.

After entering project data, the user is asked whether or not additional project data are to be entered into the data base. A negative response returns the user to the main menu, while a positive response presents the 


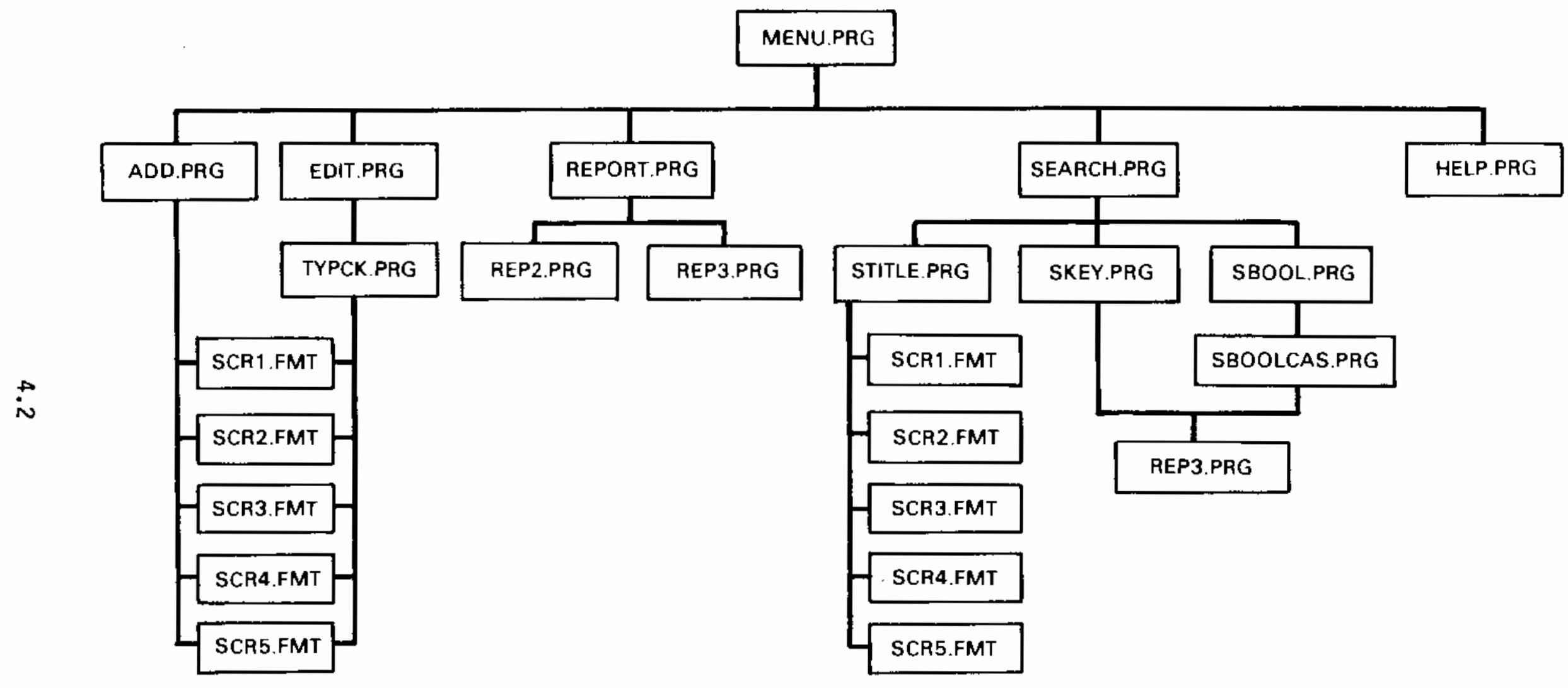

FIGURE 4.1. HEC Data Base Program Structure 
user with the first data entry screen for input of the information. The following two subsections provide instructions for entering character/numeric data and textual data.

4.2.1 Entering Character and Numeric Data

All items, with the exception of the project description, project justification, and project schedule, are stored in character or numeric fields. A11 numeric and character data should be stored in the data base in capital letters. Thus, before entering data, press the "Caps Lock" key. To enter data, type the requested information in the highlighted spaces provided on the formatted screens. If information is not entered in a given space, the data base will automatically store zeroes in numeric fields and blanks in character fields.

If the data completely fills the space provided, the cursor will automatically jump to the next item. If the data does not completely fill the highlighted space, use the RETURN key to move to the next data item. The arrows on the right of the keyboard can be used to position the cursor at the desired location. When you are finished entering the data on a particular screen, press "PgDn" to go to the next screen. Once you have exited a screen you will not be able to go back to it whlle in the ADD program. If you want to change data items that you have entered on a previous screen, refer to Section 4.3 of this User Manual.

Tabie 4.1 provides a list of commands that may be helpful in entering character and numeric data.

Table 4.1. Summary of Commands Useful for Data Entry "Ctrl/Y" Deletes all data to the right of the cursor in a given field "Del" or "Ctrl G" Deletes the character at the cursor position

"RETURN" Moves the cursor to the next data item

"PgDn" or "Esc" Moves the cursor to the next formatted screen

"Ins" When on, any text that is typed is inserted at the cursor position. When off, any text is typed over the top of existing text. on/off indicator is displayed in the upper right-hand corner of the screen. 


\subsubsection{Entering the Project Description, Project Justification, and Project Schedule}

The project description, project fustification, and project schedule are stored in memo fields. The dBase III plus text editor is used to enter data . into the memo fields. When the description/justification/schedule screen comes up, move the cursor to the box that says "memo" next to the title "project description". Typing "Ctrl PgDn" puts the user in the text editor. At this time textual description information may be entered into the data base. After entering the project description, type "Ctrl PgUp" to exit the editor. Entering the project justification and project schedule is performed in a similar manner. Text need not be entered in capital letters. When entering text it is not necessary to use the return key or hyphenate words.

\subsection{EDITING DATA}

The data edit program (EDIT.PRG) allows the modification of project information that is already stored in the data base. The EDIT program is executed when the EDIT option is selected from the main applications menu. This program requests the title of the project to be edited and then locates it. The title must be entered exactly or the proper information will not be located. If the user is unsure of the exact title, he should generate an abbreviated hard-copy of each profect file using the print option.

If the title cannot be located in the data base, the user will be asked if he wants to enter another title. A positive response asks for the new title, while a negative response returns the user to the main menu. If the title is located in the data base, the user is presented with another menu from which he can elect to edit all the data (Option 10) for the project or edit only a specified piece of data (Options 1-9). Selecting Option 10 will cause each of the formatted data screens to be presented sequentially, whereas the other options only display the pertinent data screen(s). The screens display the information that is currently in the data base for the project title that was entered. To make corrections, the new data is simply typed over the existing data, with the "Ins" key off.

After the screen is edited, "PgDn" will call up the next formatted screen if Option 10 was selected, or the user will be asked if he would like to ask 
additional information for this project if option 1 - 9 was selected. A yes $(Y)$ response returns the user to the menu where the type of information to be edited is selected. If no (N) is entered, the user is then asked if he wants to edit data for another project. If an affirmative answer is given to this question, the user is requested to enter the title of the new project to be edited. If a negative response is given, the user is returned to the main applications menu.

\subsection{ON-SCREEN SEARCH}

The on-screen search program (SEARCH.PRG) is executed when the search option is selected from the applications menu. SEARCH allows the user to search the data base for a given project title, for a combination of keywords, or for a combination of field constraints combined in a Boolean expression. Each of these options is discussed in more detail in the following sections.

\subsubsection{Title Search}

The title search program (STITLE.PRG) is called from the SEARCH program when the user selects option 1 from the search menu. The user is first asked to enter the title of the project which is the object of the search. If the title is not found, the user is given the option to enter another title, return to the search menu, or return to the application menu. If the title is found, a menu is provided which allows the user to elect to display all or selected information for that project on the screen. Project data is displayed on the same formatted screens used in the data entry and data edit programs. After viewing the data, press "PgDn" twice. The user can then elect to: (1) display additional information for the project, (2) search for another project title, (3) return to the search menu, or (4) return to the applications menu.

\subsubsection{Keyword Search}

The keyword search program (SKEY.PRG) is executed when option 2 is selected from the search menu. A formatted screen is provided in which the user can enter up to six keywords. The keywords are entered along with a keyword code which indicates the type of keyword (i.e., area, contractor, energy form saved, or other). A list of keyword codes is provided on the screen. Keywords may be all of one type or all different types. The program 
automatically searches the keyword data base (HPLKEY.DBF) for projects that list the keyword combination specified by the user. If multiple keywords are specified, a project must list all the specified keywords in its record of keywords in order to satisfy the keyword search. The screen will display the number of projects that list the specified keywords and the percentage of the total number of projects in the data base that this represents.

For the projects that list the specified keywords, the user can elect to: (1) display the titles on the screen, (2) print the titles, or (3) print project description sheets for each of the projects. Alternatively, the user can elect to return to the search menu or the applications menu at this point.

\subsubsection{Boolean Search}

The Boolean search program (SBOOL.PRG) is executed when option 3 is selected from the search menu. This program allows the user to sort the data base on a combination of up to six field constraints. The following example, which has three field constraints, will be used to illustrate the use of the Boolean search program:

All projects pertaining to the 300 Area which have a budget of more than $\$ 10,000$ per year and for which Steve Weakley is the project manager.

The first screen in the Boolean search program prompts the user to enter up to six field name/field type/operator/data constraints. The screen is formatted for ease of data entry. The field is entered first followed by an " $N$ " or a " $C$ " to indicate whether it is a numeric or character field, respectively. A list of the field names and their corresponding field types that can be used with the Boolean search option is provided in Table 4.2. Next, the desired relational operator is entered. The equal to $\Leftrightarrow$ and not equal to (\#) operators can be used with character or numeric data. The greater than (\rangle$)$, less than $(\langle)$, greater than or equal to (\rangle$=)$, and less than or equal to $(\Leftrightarrow)$ operators can only be used with numeric fields. Finally, the numeric or character data that is the object of the search is entered under the searchdata column. Press "RETURN" to move to the next screen position. When you have entered all the constraints for the search, press "PgDn". 
TABLE 4.2. Field Names for Boolean Search

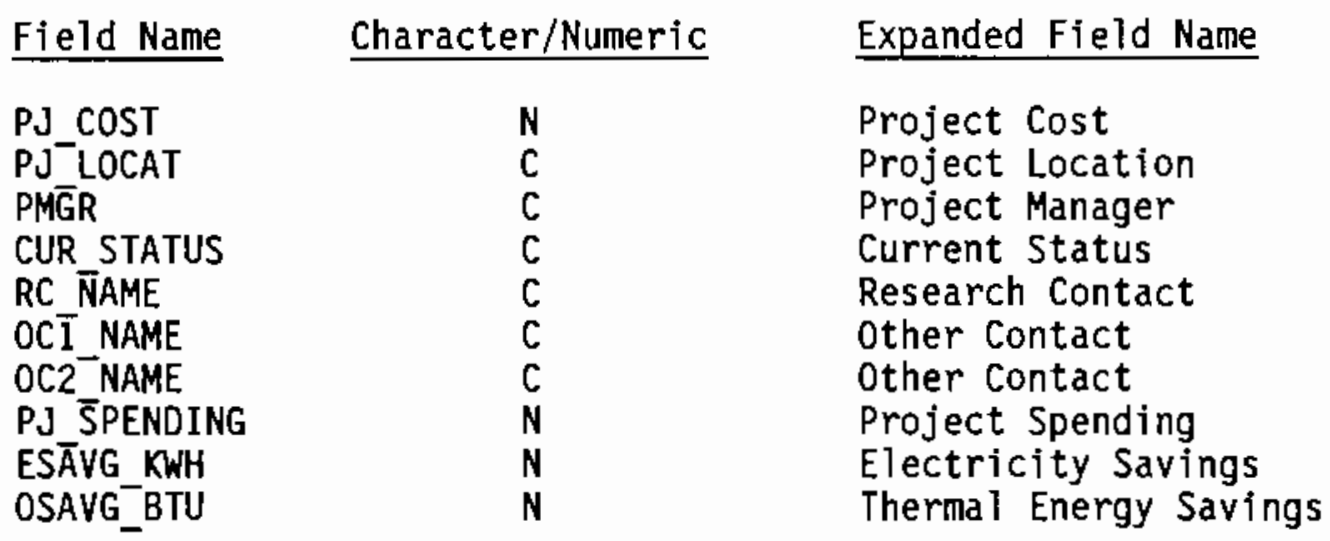

EXAMPLE:

\begin{tabular}{|c|c|c|c|}
\hline FIELD NAME & TYPE & OPERATOR & SEARCH DATA \\
\hline $\begin{array}{l}\text { PJ_COST } \\
\text { PJ_LOCAT } \\
\text { PMGR }\end{array}$ & $\begin{array}{l}N \\
C \\
C\end{array}$ & $\begin{array}{l}> \\
= \\
=\end{array}$ & $\begin{array}{l}10000 \\
300 \text { Area } \\
\text { Steve Weakley }\end{array}$ \\
\hline
\end{tabular}

The next screen displays the constraints that have been entered. Each of these is assigned a letter, beginning with $A$. The user is then asked to combine the constraints into a Boolean expression for the search, using the logical operators "AND" and "OR" and parentheses as needed for grouping.

\section{EXAMPLE:}

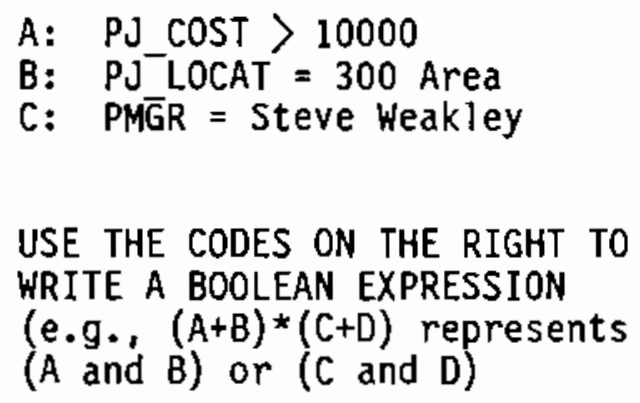

USE THE CODES ON THE RIGHT TO WRITE A BOOLEAN EXPRESSION (e.g., $(A+B) *(C+D)$ represents $(A$ and $B$ ) or ( $C$ and $D$ )

$\begin{array}{cc}\text { CODE } & \text { LOGIC OPERATOR } \\ * & \text { OR } \\ + & \text { AND }\end{array}$


User Types: $A+B+C$

Program displays the following expression:

PJ_COST > 10000 AND PJ_LOCAT $=' 300$ AREA' AND PMGR $=$ 'Steve Weakley'

Press any key to continue...

The program then searches the data base for projects that meet the specified constraints. It sums the number of projects that meet the constraints and displays this information on the screen along with the percentage of the total number of projects in the data base represented by this subset.

EXAMPLE: $\quad 2$ PROJECTS(S), MEET THE FOLLOWING CRITERIA:

PJ_COST $=10000$ AND. PJ_LOCAT $=' 300$ AREA' AND. PMGR $=$ 'Steve Weakley' THIS REPRESENTS :

$20 \%$ OF THE 10 HANFORD ENERGY CONSERVATION PROJECTS

Press any key to continue...

For the projects that meet the constraints, the user can elect to: display the titles on the screen, (2) print the titles, or (3) print project description sheets for each of the projects. The user can elect to return to the search menu or the application menu at this point.

\subsection{PRINTING REPORTS}

Invoking the PRINT REPORT(S) option starts the report program. The user is given the option to either print expanded or abbreviated reports. Upon choosing the type of output, the user is prompted to put the printer on-line. The printer must be connected to port LPI1. Failure to put the printer online will result in premature termination of the program. After placing the printer on-line, the user is asked whether a printout for all projects is 
desired or a user-specified project is desired. Once the printout is finished the program returns to the main applications menu.

\subsection{HELP}

The HELP program (HELP.PRG) is executed when the user selects option 5 from the application menu. In the HELP program, the user is asked to select the application with which he/she would like help. A brief paragraph describing the application is shown on the screen and the appropriate section in the User Manual is indicated.

\subsection{EXITING THE APPLICATIONS PROGRAM}

The user can exit the applications program by selecting option 6 from the applications menu. This option closes all open files and returns the user to the DOS operating system.

At this point, backup copies of the data bases should be made to protect against loss of any new information that has been entered or any alternations that have been made. Backup can be accomplished from the DOS operating system with the following commands:

To backup a single file: COPY d1:filename.DBF d2:filename.DBF

To backup all data base files: COPY $d 1:^{\star}$.DBF $d 2:$

To backup all program files COPY d1:*.PRG d2:

Where $\mathrm{d} 1$ = source drive designation and $\mathrm{d} 2$ = destination drive designation. The following files should always be backed up: HPLAN.DBF, HPLT.NDX, HPLMEM.DBF, HPLMEM.DBT, HPLKEY.DBF. 


\section{.}




\section{APPENDIX A}

AN OVERVIEW OF DBASE III PLUS 
APPENDIX A

\section{AN OVERVIEW OF dBase III Plus}

dBASE III Plus is a relational data base management system for the IBM$P C$ and compatible microcomputers. The software was developed by Ashton-Tate corporation for maintaining and manipulating data stored in relational data bases. A relational data base organizes data as a two-dimensional table consisting of rows and columns. Each column defines a data field, and each row defines a data record. Thus, each data record (row) is divided into data fields (columns). The data base consists of a set of data records. The names of the data fields and type of data stored in each field are specified in the data structure of the data base.

dBASE III Plus can be used in two processing modes: interactive command processing and batch command processing. In the interactive command mode, data in the data base are manipulated by individually entering English-like commands from the keyboard. After each command is entered, the results are displayed on the computer screen or printer.

In the batch command mode, data processing tasks are defined by writing a set of command procedures using the dBASE III Plus programming language. The collection of commands is stored in a command file, which constitutes a computer program. These commands are then executed as a batch file. The batch command was used to develop the menu-driven software for the HEC project data base that allows users to select and execute specific data management tasks from menus displayed on the computer screen.

The availability of two processing modes makes dBASE III a flexible and powerful data base management system. It allows the user to perform a wide range of data processing and computational tasks to manage a relational data base. These tasks can range from simple to complex data base applications. Examples of the more commonly performed tasks are as follows:

1. Add new data to the data base, change part or all of the contents of the data base, and delete items from the data base.

2. Sort or rearrange the data records in the data base into a userspecified sequence or order. 
3. Locate and display data fields that satisfy user-specified conditions.

4. Display customized formatted reports.

5. Do arithmetic calculations with the data, such as totals, averages, etc.

6. Link together multiple relational data bases through common data fields.

7. Build command files using the dBASE III programming language to create menu-driven systems that enable the beginning user to select options from displayed menus in order to perform selected data management tasks.

The complete repertoire of dBASE III Plus commands is documented in the user manual published by the developer, Ashton-Tate (1). Other publications that will introduce the user to the capabilities of dBASE III Plus are listed in the bibliography (2-4). The user that elects to bypass the menu-driven interface to the HEC project data base and instead use the dBASE III commands to access the data base may want to consult these publications.

\section{BIBLIOGRAPHY}

Ashton-Tate. 1984. dBASE III Plus User Manual. Ashton-Tate, 10150 West Jefferson Boulevard, Culver City, CA 90230.

Simpson, Alan, 1985. Understanding d8ASE III.

Sybex, Inc., 2344 sixth Street, Berkeley, CA 94710.

Jones, Edward. 1985. Using dBASE III.

Osborne McGraw-Hi11, 2600 Tenth Street, Berkeley, CA 94710.

Chou, George Tsu-der. 1985. dBASE III Handbook.

Que Corporation, 7999 Knue Road, Indianapolis, IN 46250.

Carrabis, Joseph-David. 1985. dBASE III Advanced Programming. 
APPENDIX B

PROGRAM LISTINGS 


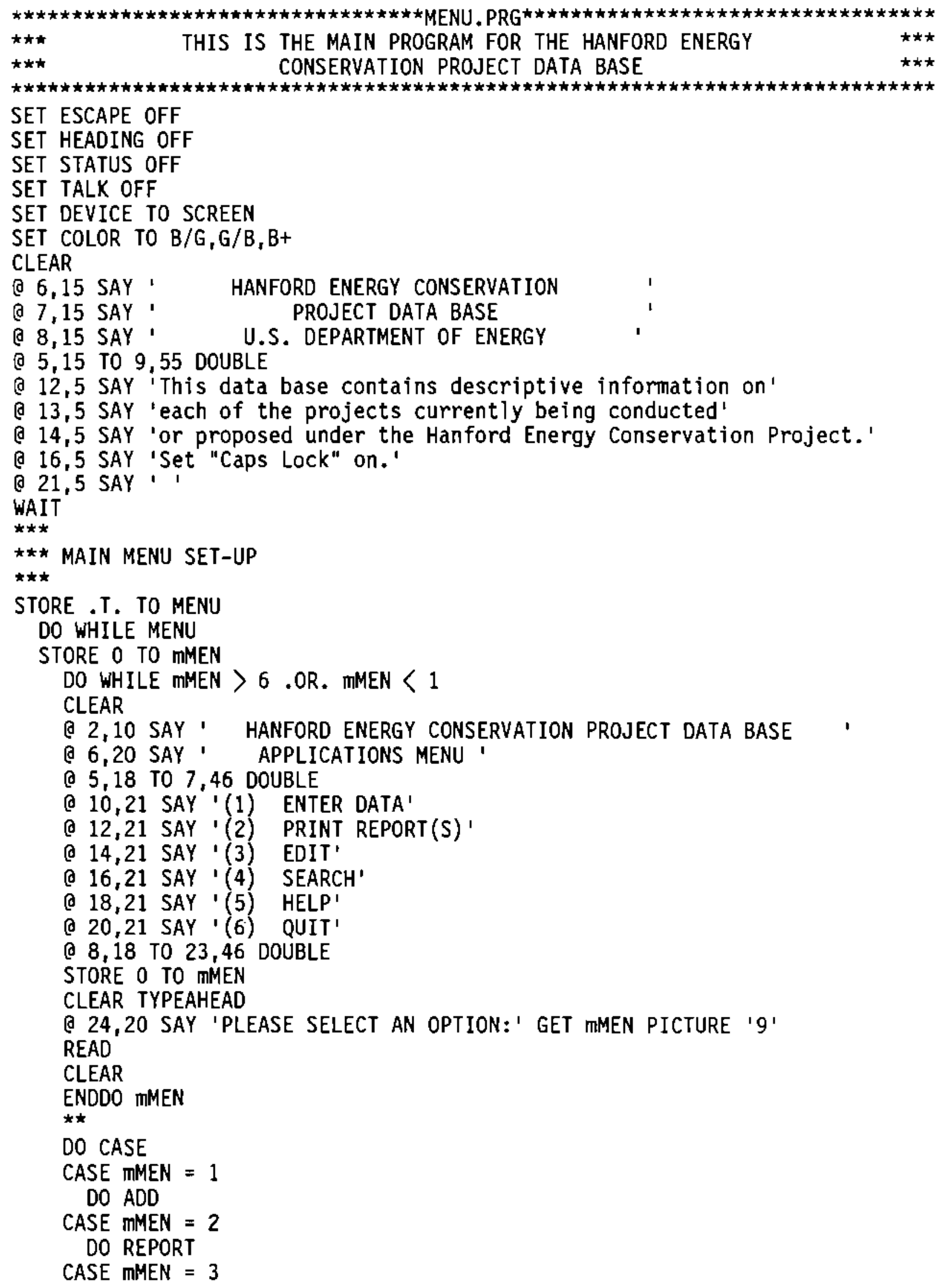




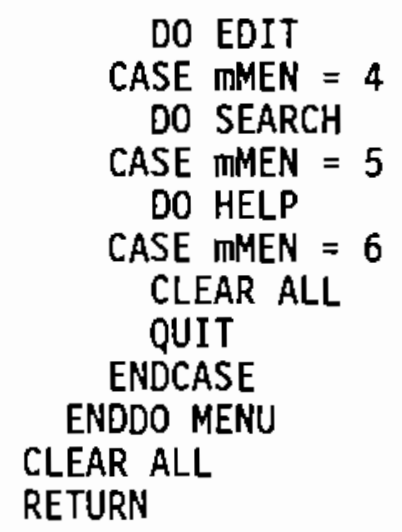




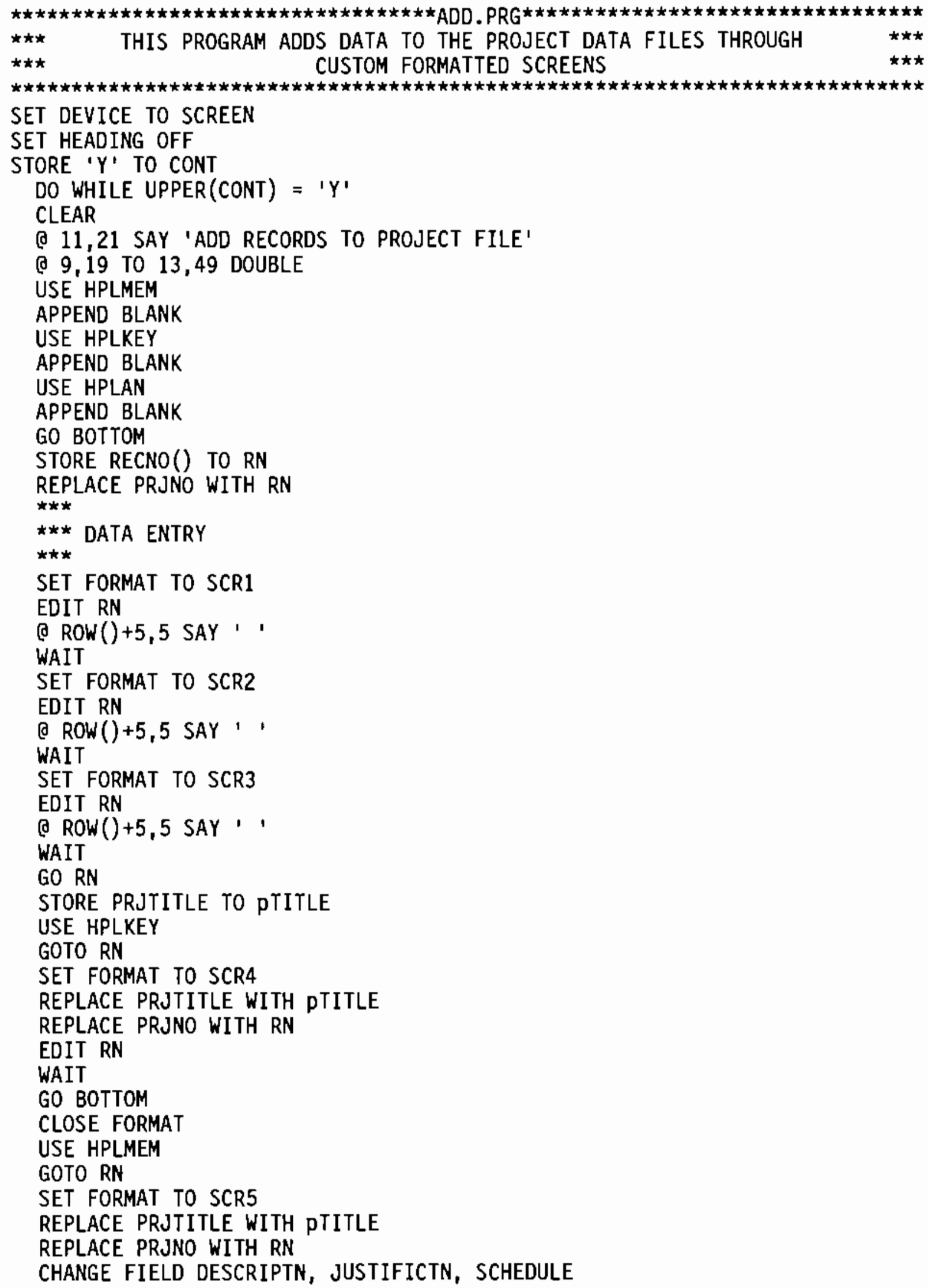




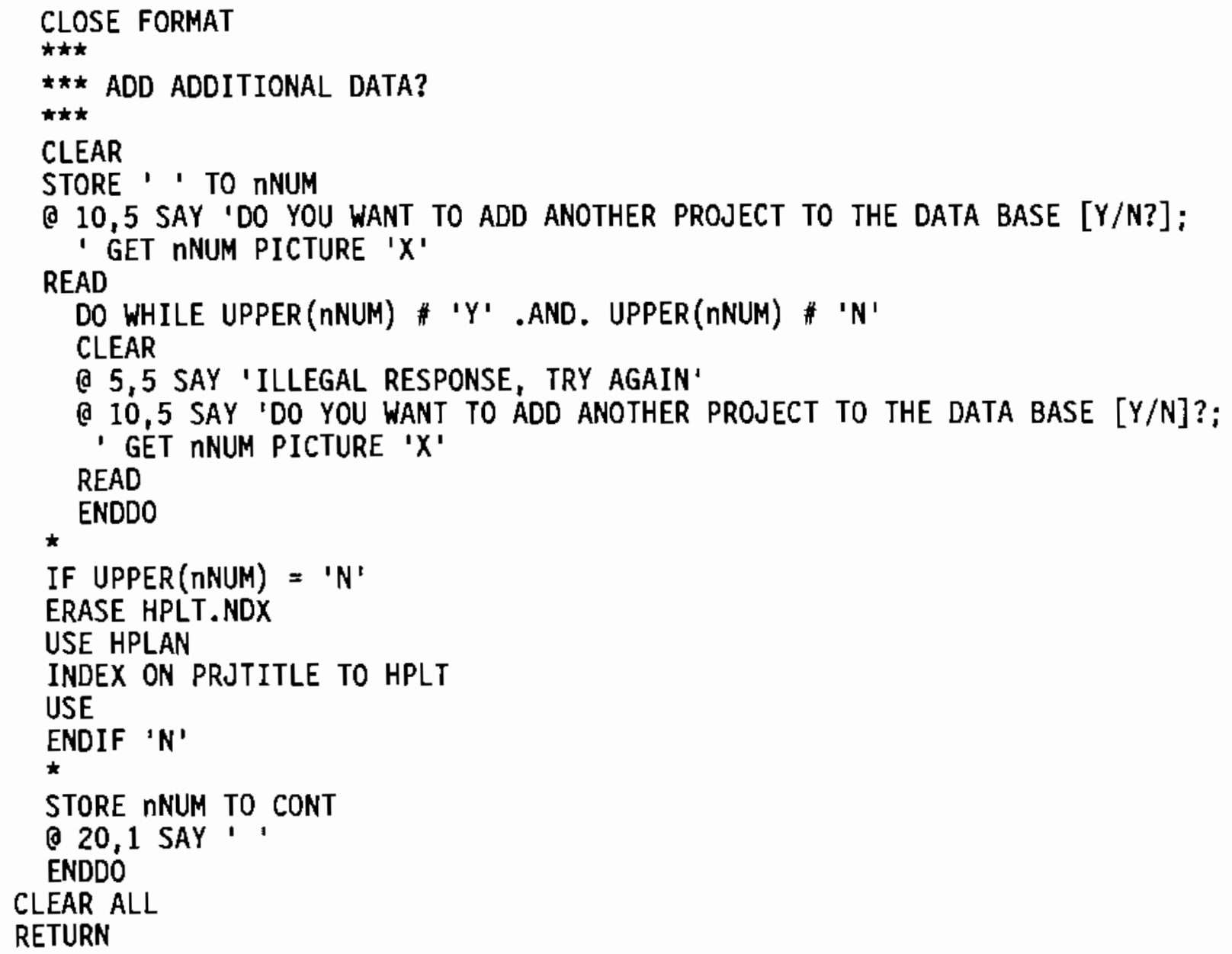




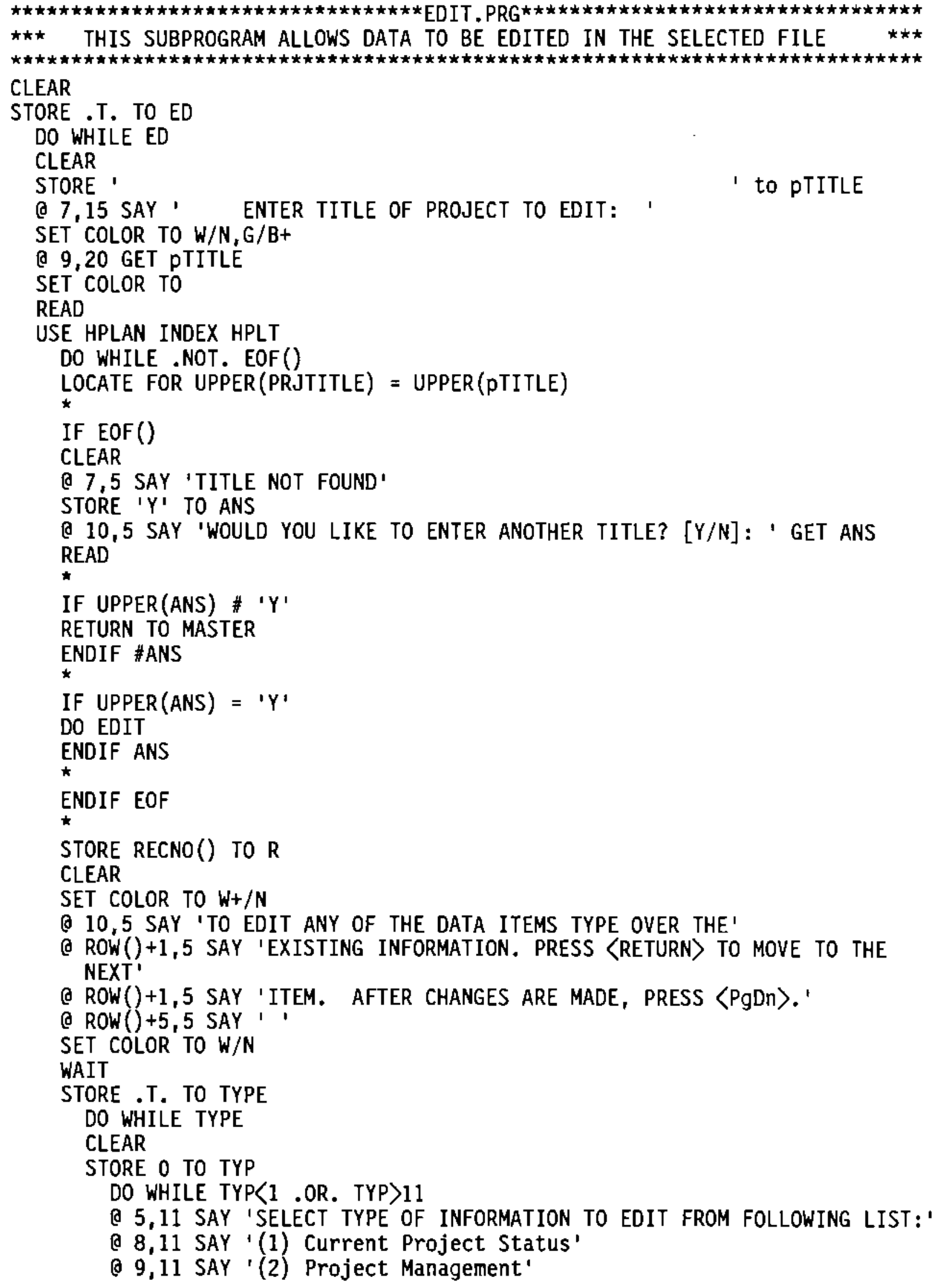




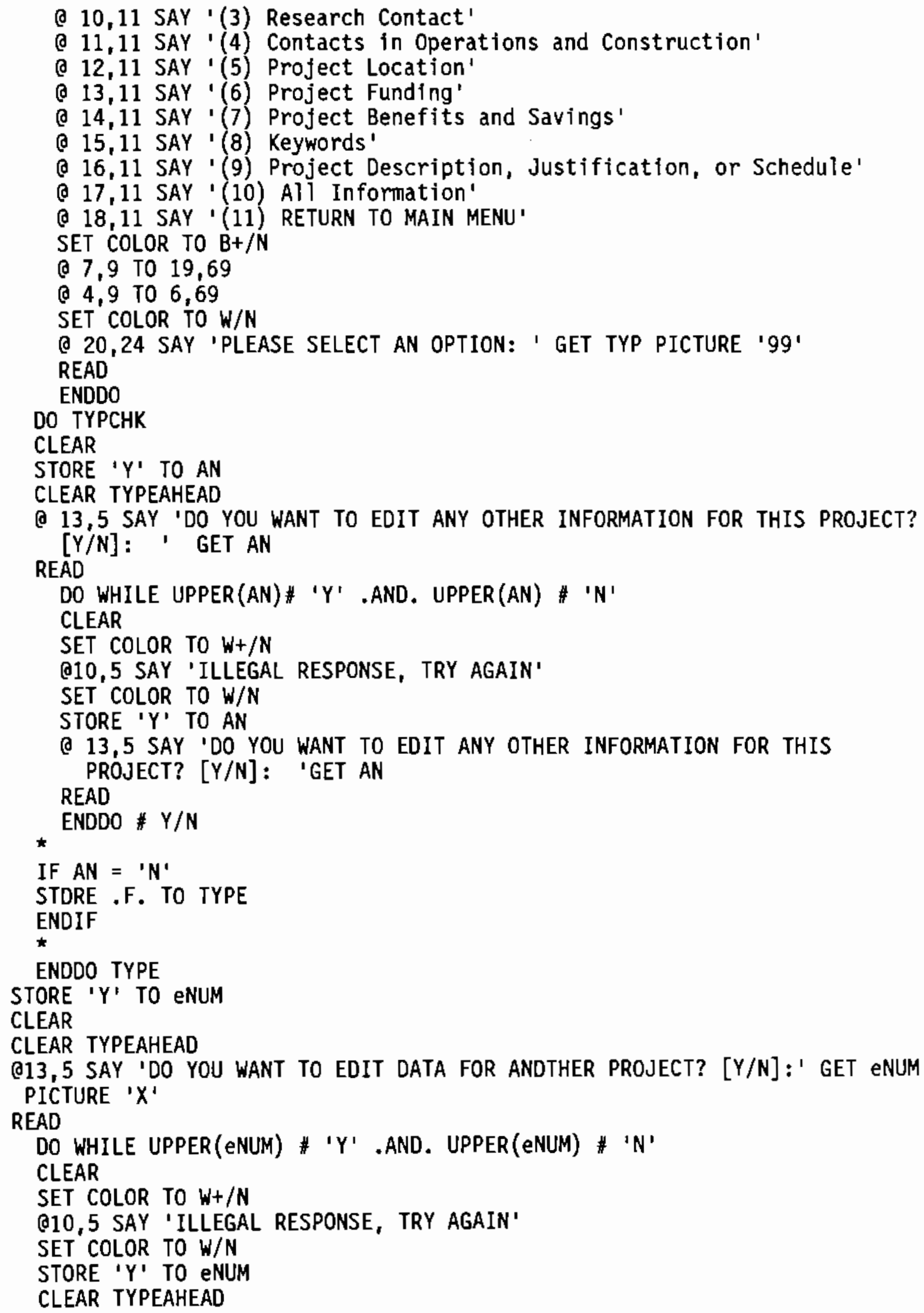




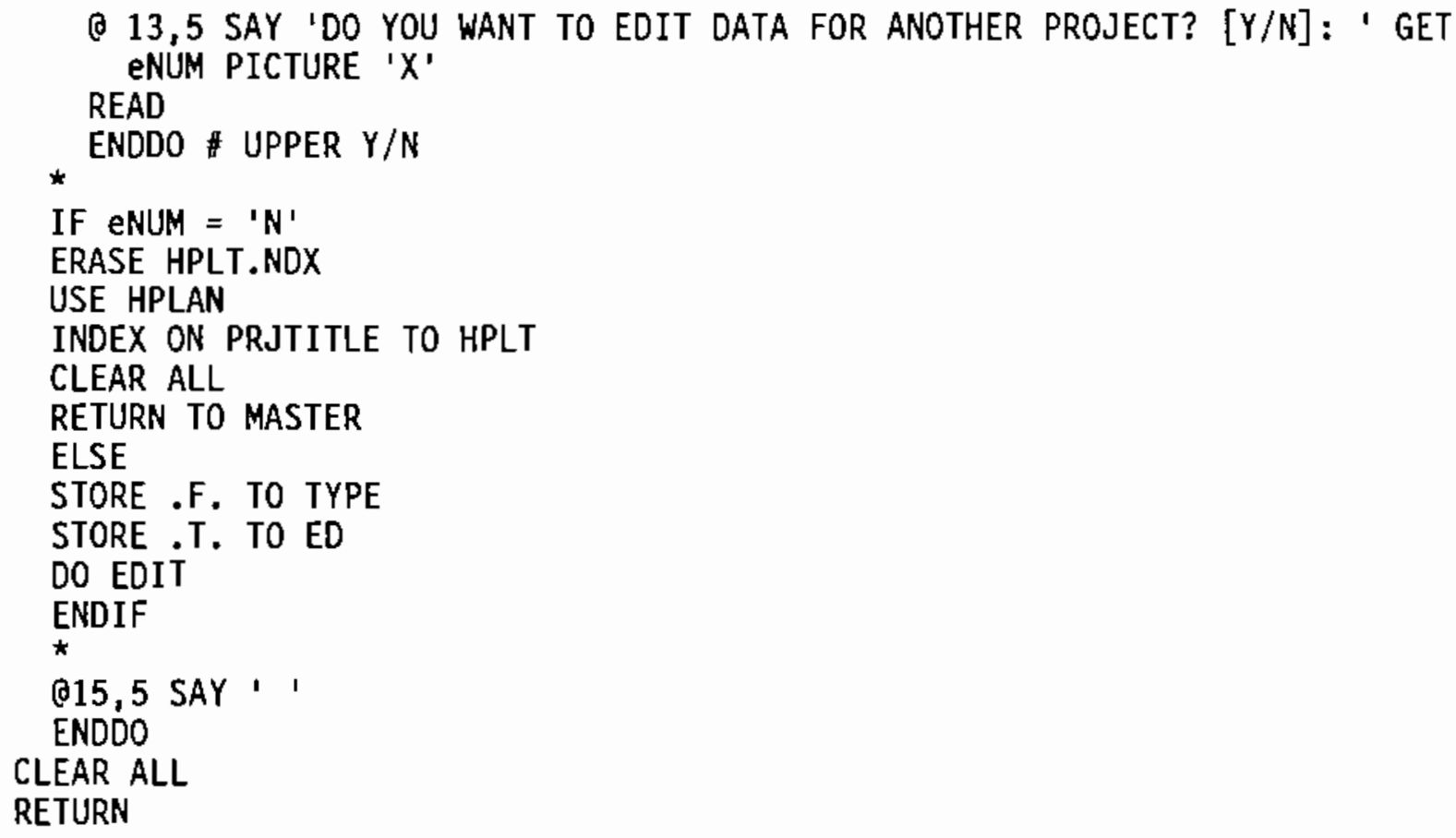




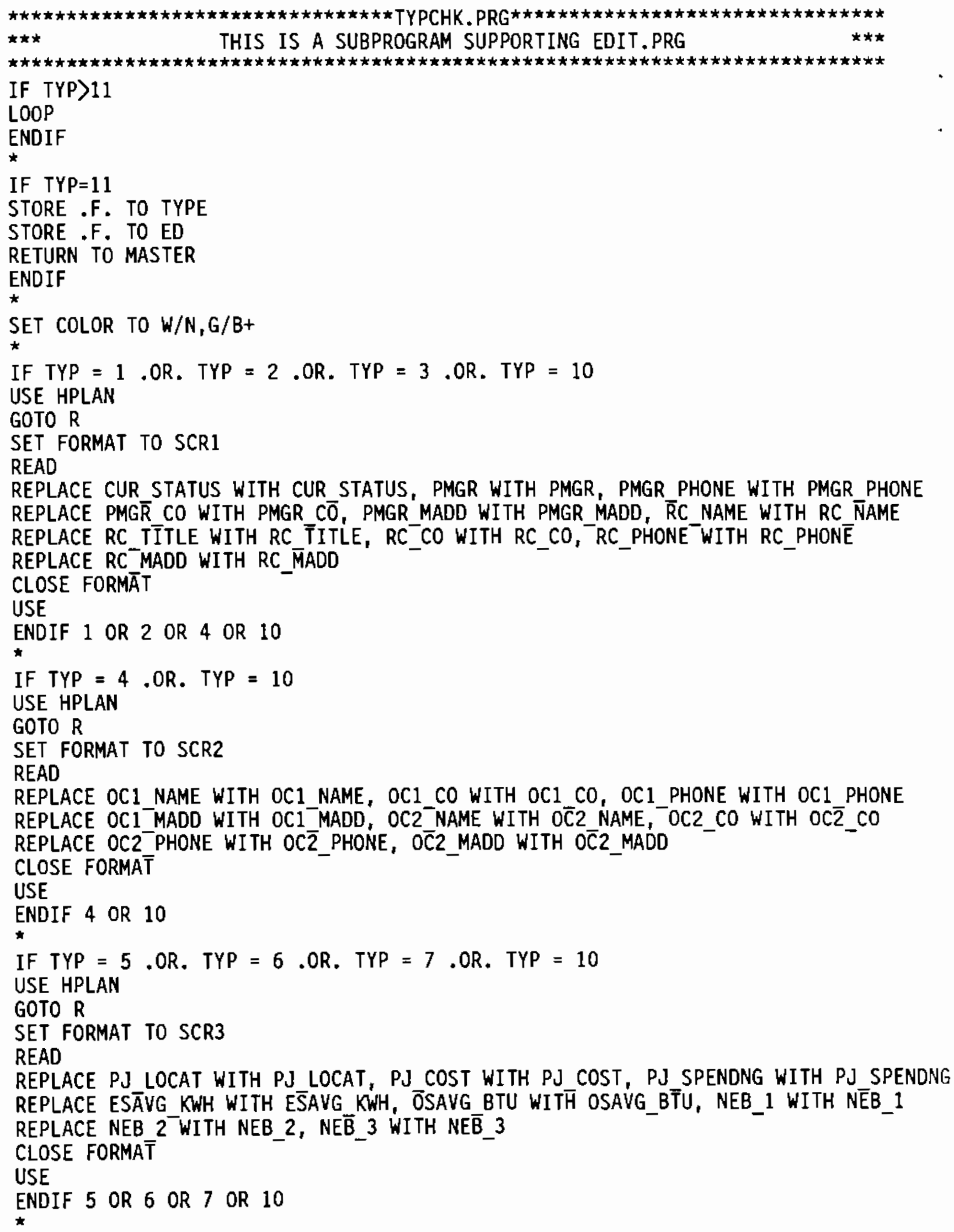




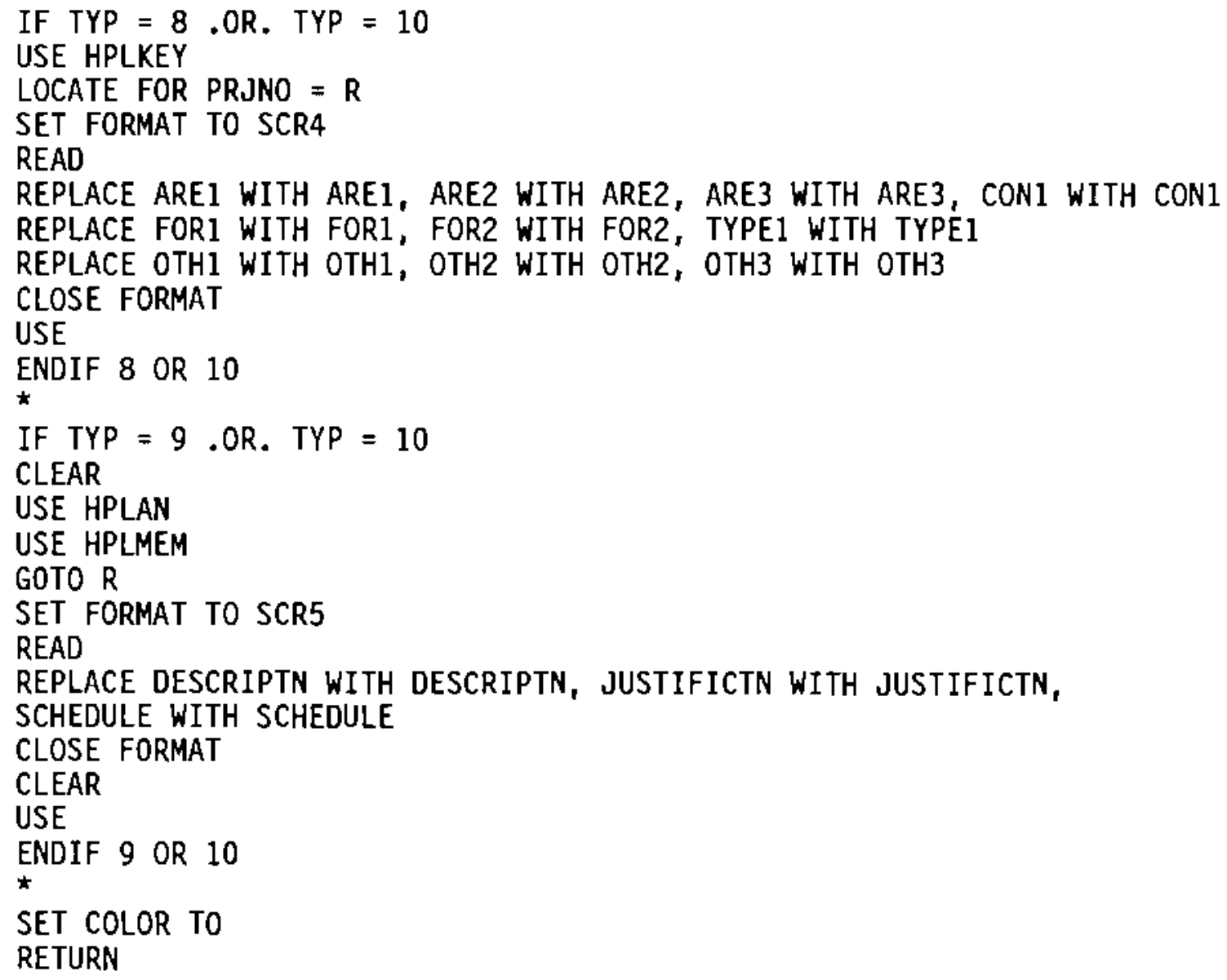




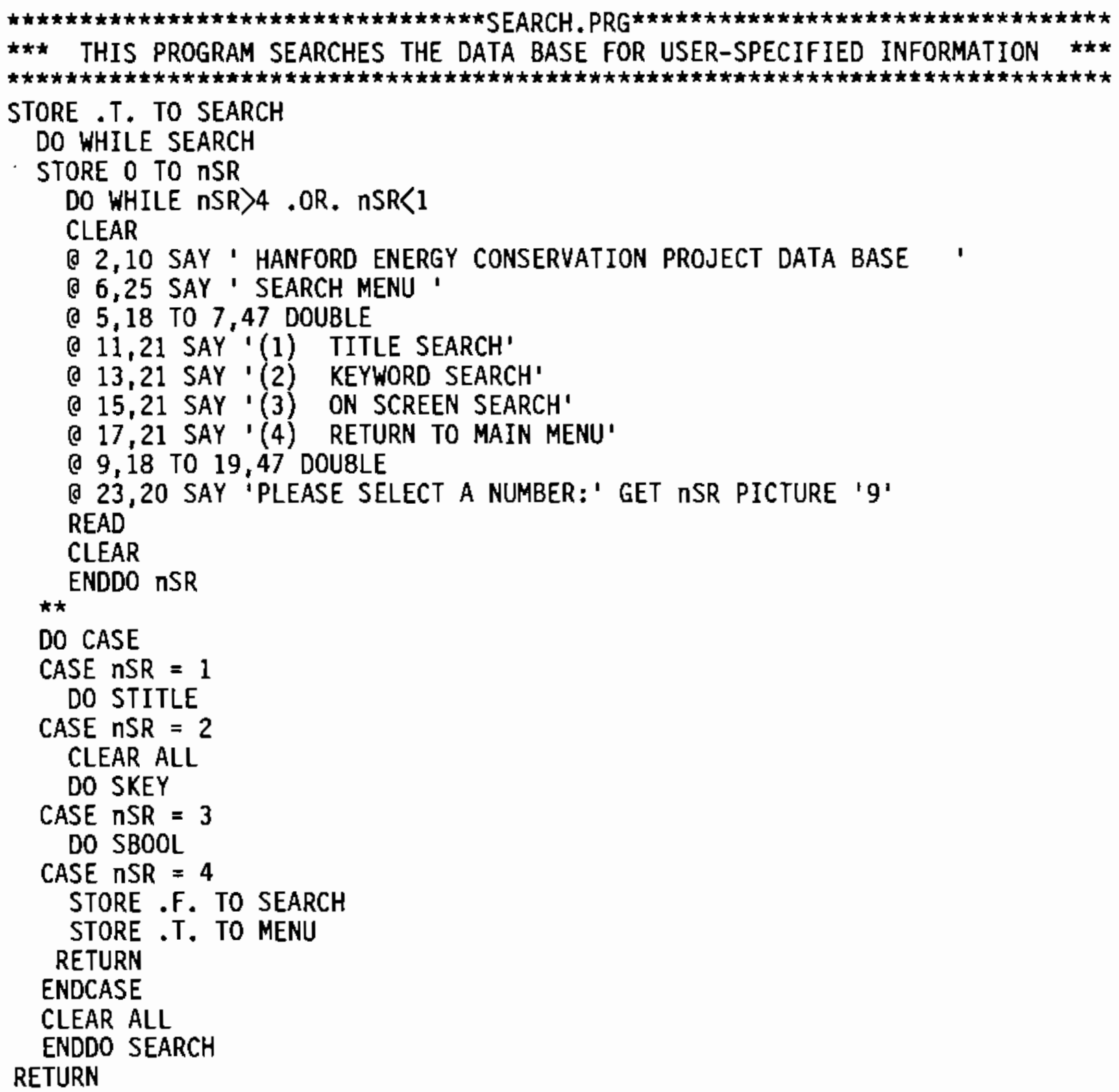




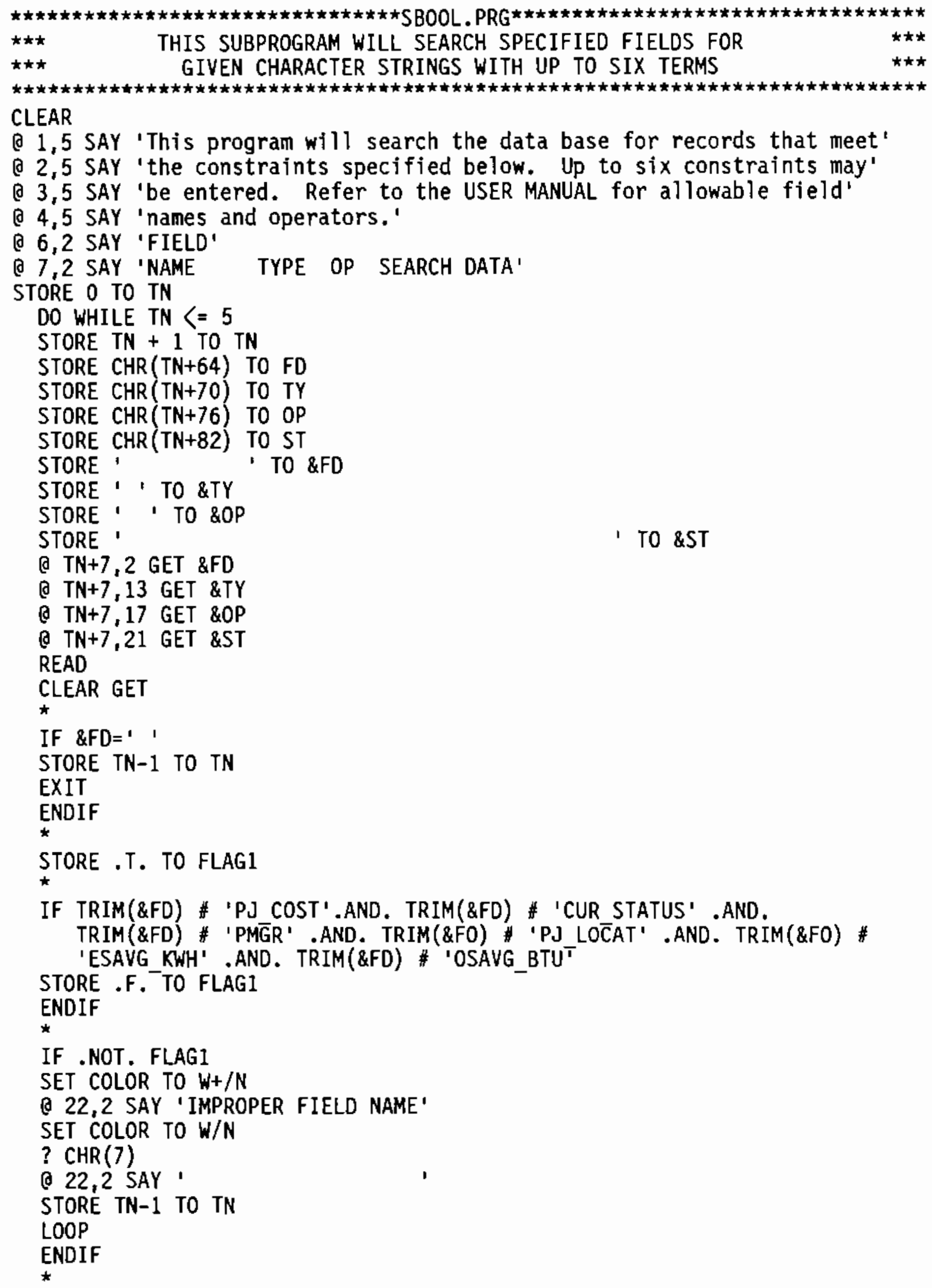

CLEAR

a 1,5 SAY 'This program will search the data base for records that meet'

(0) 2,5 SAY 'the constraints specified below. Up to six constraints may'

a 3,5 SAY 'be entered. Refer to the USER MANUAL for allowable field'

a 4,5 SAY 'names and operators.'

a 6,2 SAY 'FIELD'

D 7,2 SAY 'NAME TYPE OP SEARCH DATA'

STORE 0 TO TN

DO WHILE TN $<=5$

STORE TN +1 TO TN

STORE CHR (TN+64) TO FD

STORE CHR (TN+70) TO TY

STORE CHR (TN+76) TO OP

STORE CHR (TN+82) TO ST

STORE

STORE ' ' TO \&TY

STORE ' ' TO \&OP

STORE

- TO \&FD

(2) $\mathrm{TN}+7,2$ GET \&FD

(a) $\mathrm{TN}+7,13$ GET \&TY

(2) $\mathrm{TN}+7,17$ GET \&OP

(a) TN+7,21 GET \&ST

READ

CLEAR GET

ネ

IF $\& F D=1 \quad$ ।

STORE TN-1 TO TN

EXIT

ENDIF

$\star$

STORE . T. TO FLAG1

IF TRIM(\&FD) \# 'PJ COST'.AND. TRIM(\&FD) \# 'CUR STATUS' .AND. TRIM(\&FD) \# 'PMGGR' .AND. TRIM(\&FO) \# 'PJ LOC̄AT' .AND. TRIM(\&FO) \#

'ESAVG_KWH' .AND. TRIM(\&FD) \# 'OSAVG_BTU'

STORE .F. TO FLAGI

ENDIF

*

IF . NOT. FLAGI

SET COLOR TO $W+/ N$

Q 22,2 SAY 'IMPROPER FIELD NAME'

SET COLOR TO $W / N$

? $\mathrm{CHR}(7)$

(d) 22,2 SAY '

TO \&ST

STORE TN-1 TO TN

LOOP

ENDIF

* 
IF \&TY \# ' $N$ ' .AND. \&TY \# ' $C$ '

STORE .F. TO FLAG1

\section{ENDIF}

IF .NOT. FLAG1

SET COLOR TO $W+/ N$

B22,2 SAY 'IMPROPER FIELD TYPE'

SET COLOR TO W/N

?CHR(7)

Q22,2 SAY '

STORE TN-1 TO TN

LOOP

ENDIF

IF $\operatorname{TRIM}(\& O P) \# '={ }^{\prime}$.AND. $\operatorname{TRIM}(\& O P) \# '\left\langle P^{\prime}\right.$.AND. TRIM(\&OP) \#'〉'

AND. TRIM(\&OP) \#' $O$ ' .AND. TRIM(\&OP) \# ' $\angle=1$.AND. TRIM(\&OP) \# i) $=$ '

STORE .F. TO FLAG1

ENDIF

$\star$

IF . NOT. FLAGI

SET COLOR TO W+/N

O 22,2 SAY 'IMPROPER OPERATOR'

SET COLOR TO $W / N$

?CHR(7)

a 22,2 SAY '

STORE TN-1 TO TN

LOOP

ENDIF

*

ENDDO

STORE 0 TO LINE

STORE 0 TO TC

CLEAR

DO WHILE TC<TN

STORE TC+1 TO TC

STORE CHR $(64+T C)$ TO FD

STORE CHR $(70+T C)$ TO TY

STORE CHR $(76+T C)$ TO OP

STORE CHR (82+TC) TO ST

(0 ROW ()$+1,5$ SAY FD +": "+TRIM(\&FD)+' '+ $\operatorname{TRIM(\& OP)+~"~"~+~TRIM(\& ST)+"~"~"~}$

IF UPPER $(\& T Y)=$ ' $C$ '

STORE ' '+TRIM(UPPER(\&FD))+' '+TRIM(\&OP)+" ' "+TRIM(UPPER(\&ST))+" " TO \&FD ENDIF

IF UPPER $(\& T Y)=$ ' $N$ '

STORE ' '+TRIM(\&FD)+' '+TRIM(\&OP)+' '+TRIM(\&ST) TO \&FD

ENDIF

$\star$

ENDDO WHILE TC

STORE .T. TO ERR 


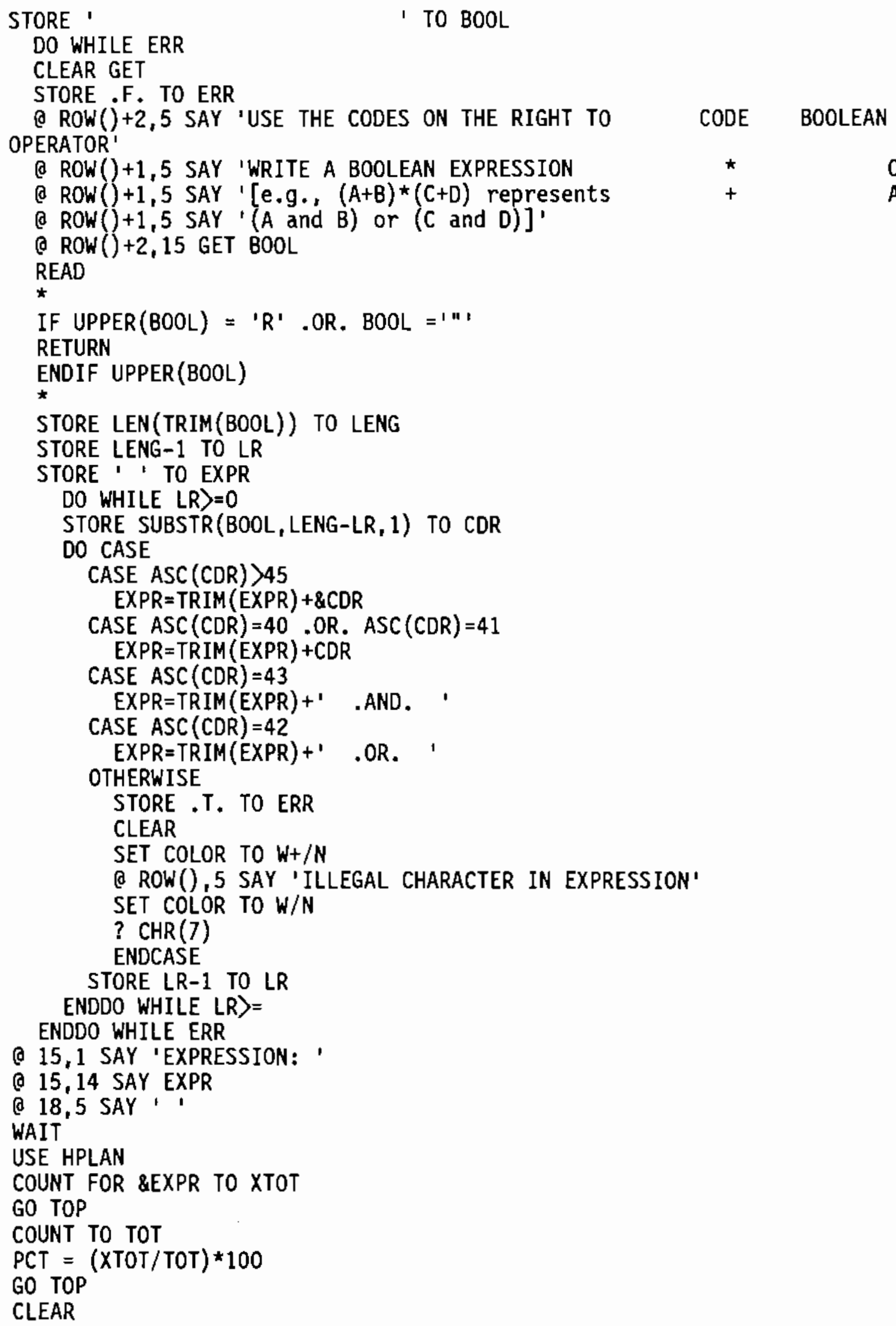




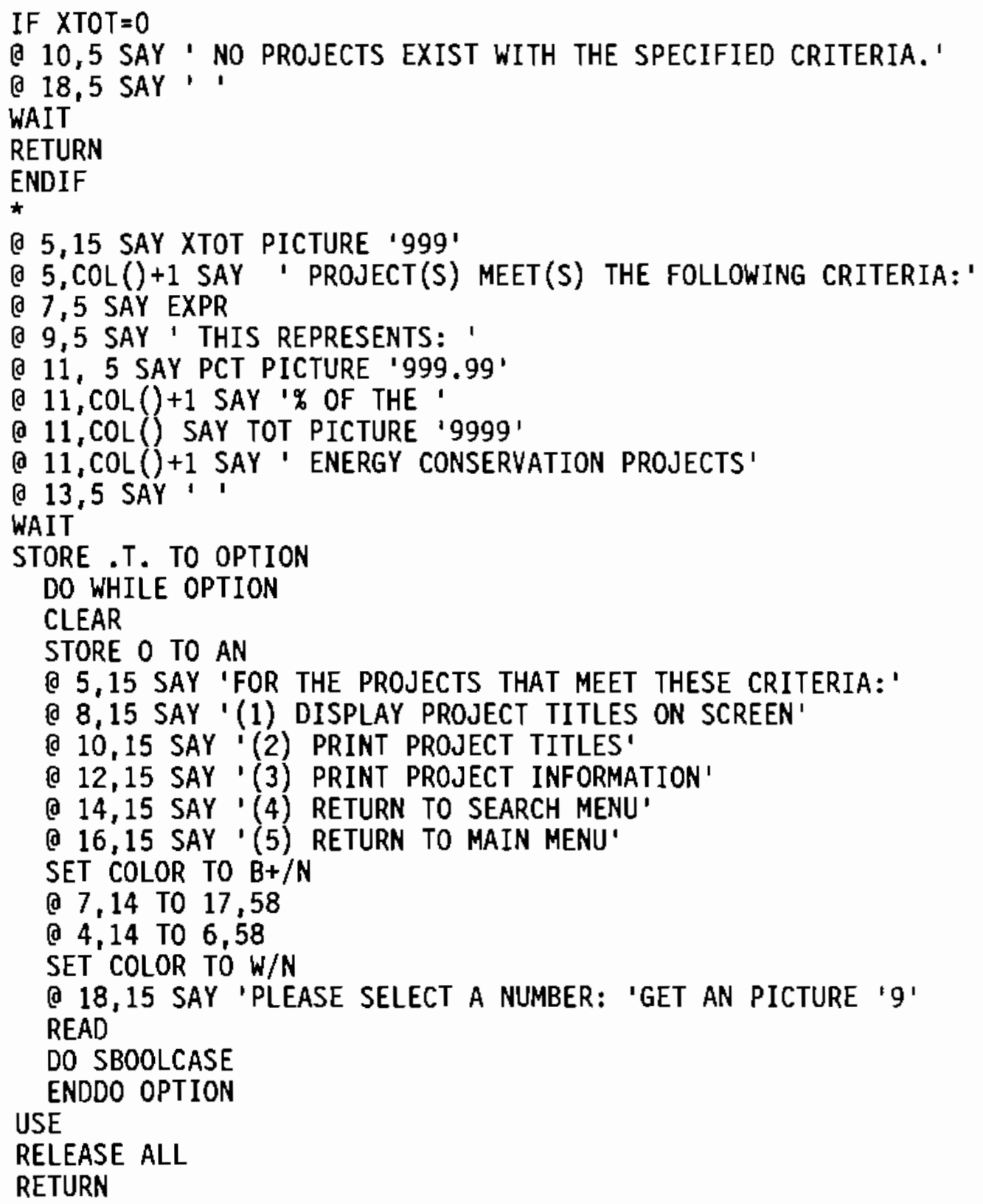




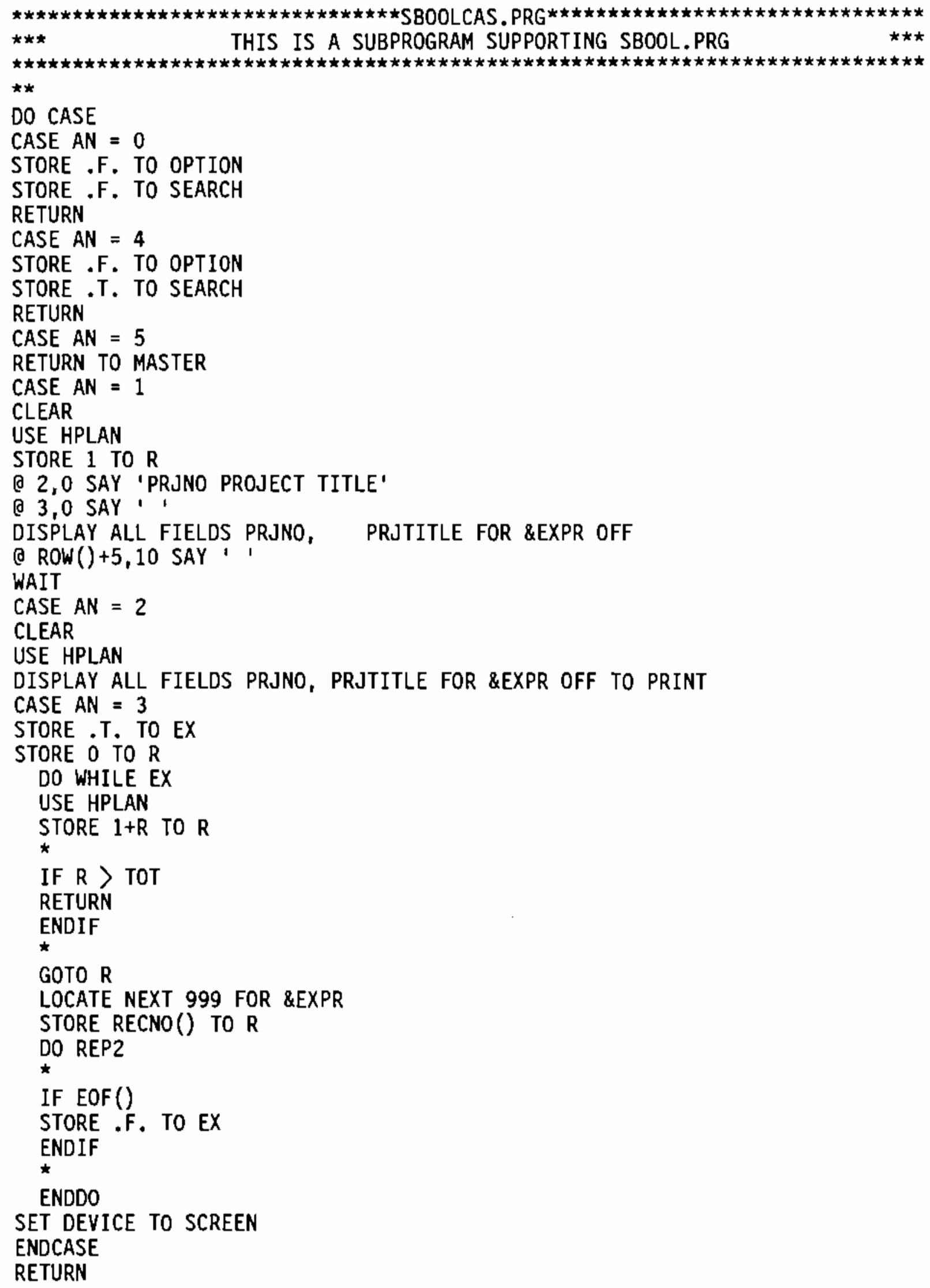




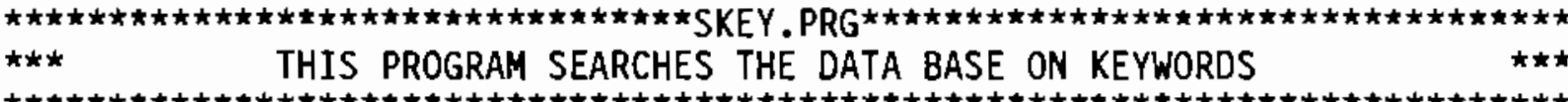

STORE .T. TO KEY

DO WHILE KEY

CLEAR

0 1,5 SAY 'YOU MAY ENTER UP TO SIX KEYWORDS. REFER TO THE LIST OF VALID'

(2 2,5 SAY 'TYPES SHOWN ON THE RIGHT AND ENTER THE ASSOCIATED CODE (e.g.,ARE) IN'

(e 3,5 SAY 'THE TYPE COLUMN. KEYWORDS CAN BE ALL ONE TYPE, OR DIFFERENT TYPES'

Q 6,5 SAY 'TYPE

KEYWORD

TYPE CODES '

Q 7,5 SAY '

STORE 0 TO TN

(c) 8,44 SAY 'AREA (ARE)'

0 9,44 SAY 'CONTRACTOR (CON)'

( 10,44 SAY 'ENERGY FORM SAVED (FOR)'

( 11,44 SAY 'ENERGY TYPE SAVED (TYPE)'

(0 12,44 SAY 'OTHER (OTH)'

DO WHILE TN $<7$

STORE TN+1 TO TN

STORE CHR (TN+64) TO TYPE

STORE CHR $(T N+70)$ TO KEY

STORE ' ' TO \&TYPE

STORE '

(O) TN+7,5 GET \&TYPE

TO \&KEY

(2) TN+7,12 GET \&KEY

READ

CLEAR GET

IF \&TYPE \# 'ARE' .AND, \&TYPE \#'' AND. \&TYPE \# 'CON' .AND. \&TYPE \# 'FOR' .AND. \&TYPE \# 'TYPE' .AND. \&TYPE \# 'OTH'

STORE TN-2 TO TN

LOOP

ENDIF

ॠ

IF \&TYPE $='$ '

STORE TN-1 TO TN

EXIT

ENDIF

$\pitchfork$

STORE .F. TO FLAG1

STORE O TO LL

DO WHILE LL<24

STORE $1+\mathrm{LL}$ TO LL

STORE CHR(LL+64) TO CODE

ネ

IF $\operatorname{TRIM}(\& C O D E)=\operatorname{TRIM}(\& T Y P E)$

STORE . T. TO FLAG1

EXIT

ENDIF

$\star$ 


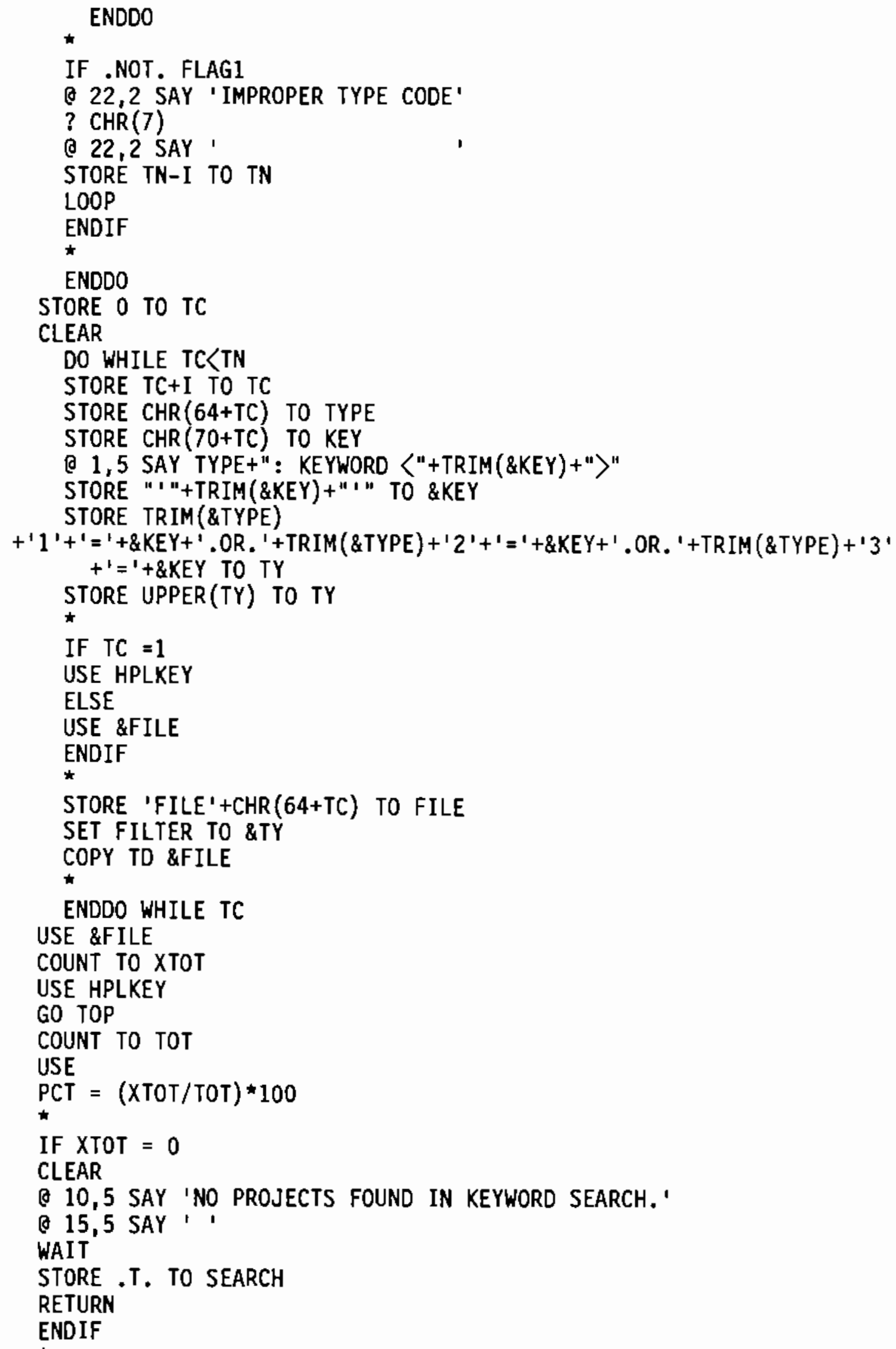




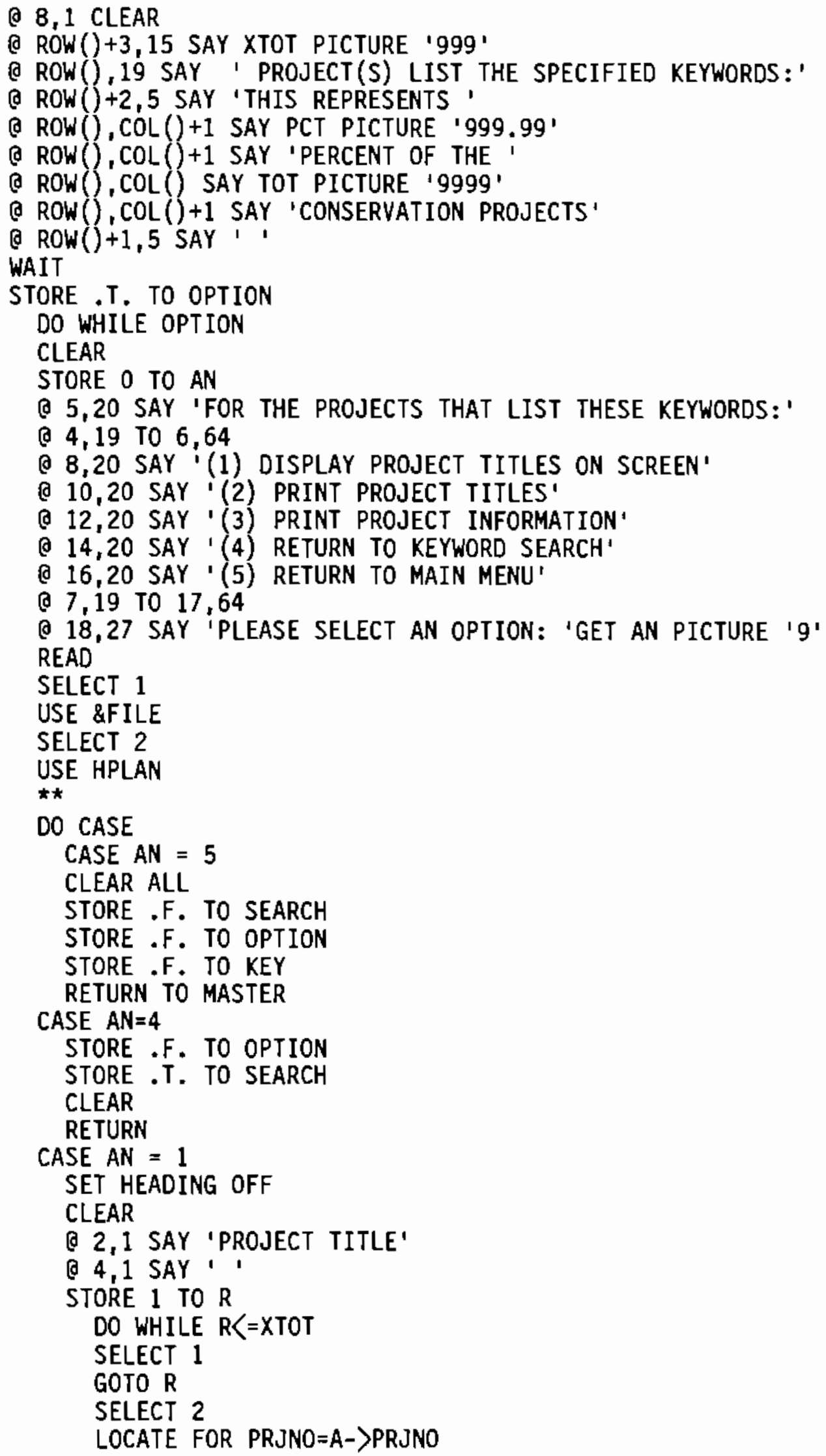




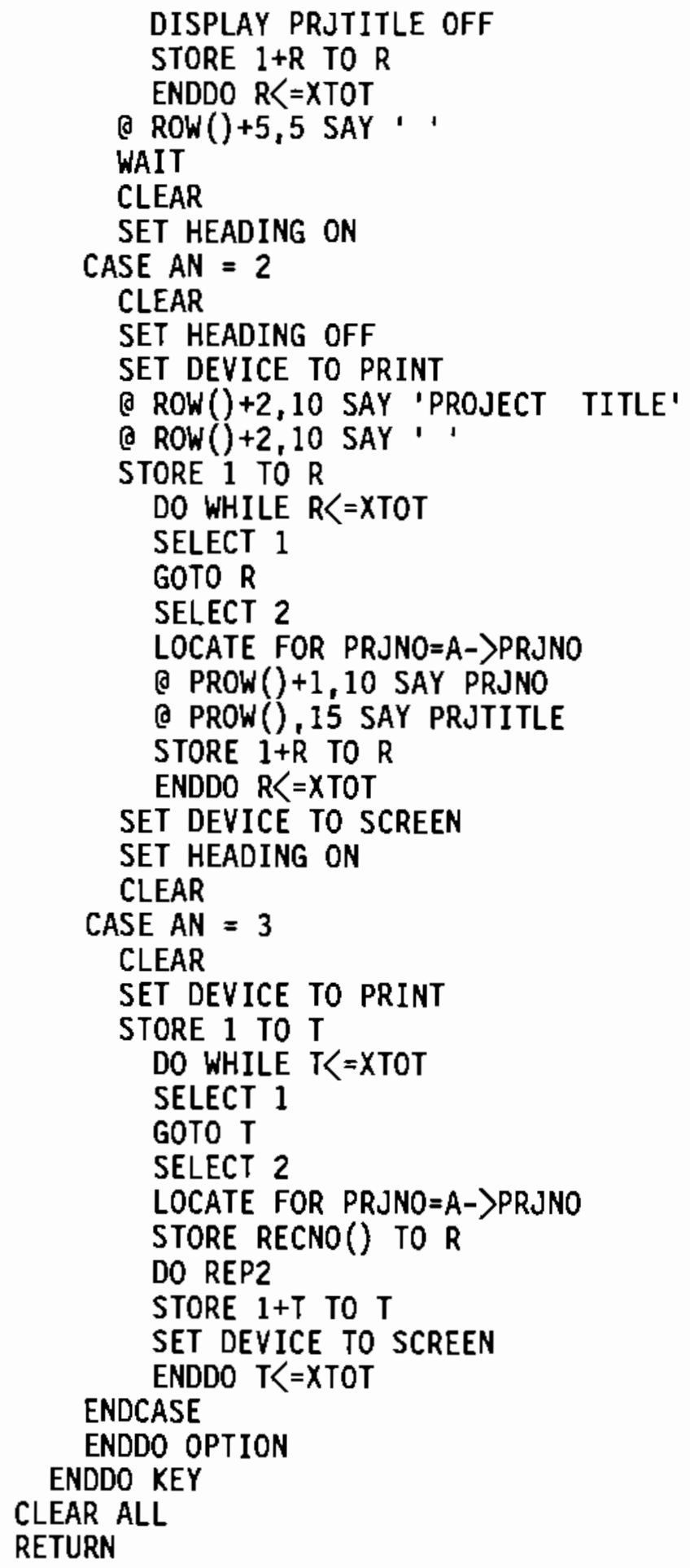




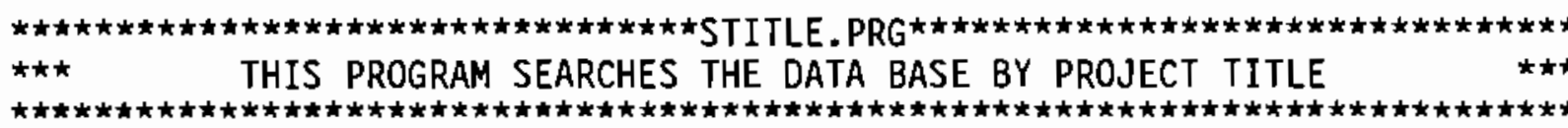

STORE .T. TO aTL

DO WHILE aTL

USE HPLAN INDEX HPLT

STORE . T. TO ST

DO WHILE ST

CLEAR

(0 ROW ()+10,15 SAY 'ENTER TITLE TO SEARCH FOR :'

(o ROW ()+3,15 SAY ' '

ACCEPT " TITLE: " TO $\mathrm{mTL}$

LOCATE FOR PRJTITLE =UPPER $(\mathrm{mTL})$

STORE PRJNO TO PNUM

STORE PRJTITLE TO mTITLE

CLEAR

$\star$

IF EOF()

CLEAR

( ROW ()$+5,33$ SAY 'TITLE NOT FOUND'

(d) ROW ()$+2,37$ SAY 'SELECT: '

(a) 6,25 TO 8,55

STORE 0 TO SEL

DO WHILE SEL $>3$.OR. SEL 1

(0 ROW ()+3,27 SAY '(1) ENTER ANOTHER TITLE'

( ROW ()$+2,27$ SAY '(2) RETURN TO SEARCH MENU'

(2 ROW()+2,27 SAY '(3) RETURN TO MAIN MENU'

(2) 9,25 TO 16,55

(O ROW()+2,27 SAY 'PLEASE SELECT A NUMBER: ' GET SEL PICTURE STORE 0 TO SEL

READ

ENDDO SEL

$\star \star$

DO CASE

CASE SEL $=1$

LOOP

CASE SEL $=2$

RETURN

CASE SEL $=3$

RETURN TO MASTER

ENDCASE

ELSE

STORE .F. TO ST

ENDIF EOF

*

ENDDO ST

SET INDEX TO HPLT

STORE . T. TO OPT

DO WHILE OPT

CLEAR

STORE 0 TO INF

DO WHILE INF $>10$.0R. INF $<1$ 


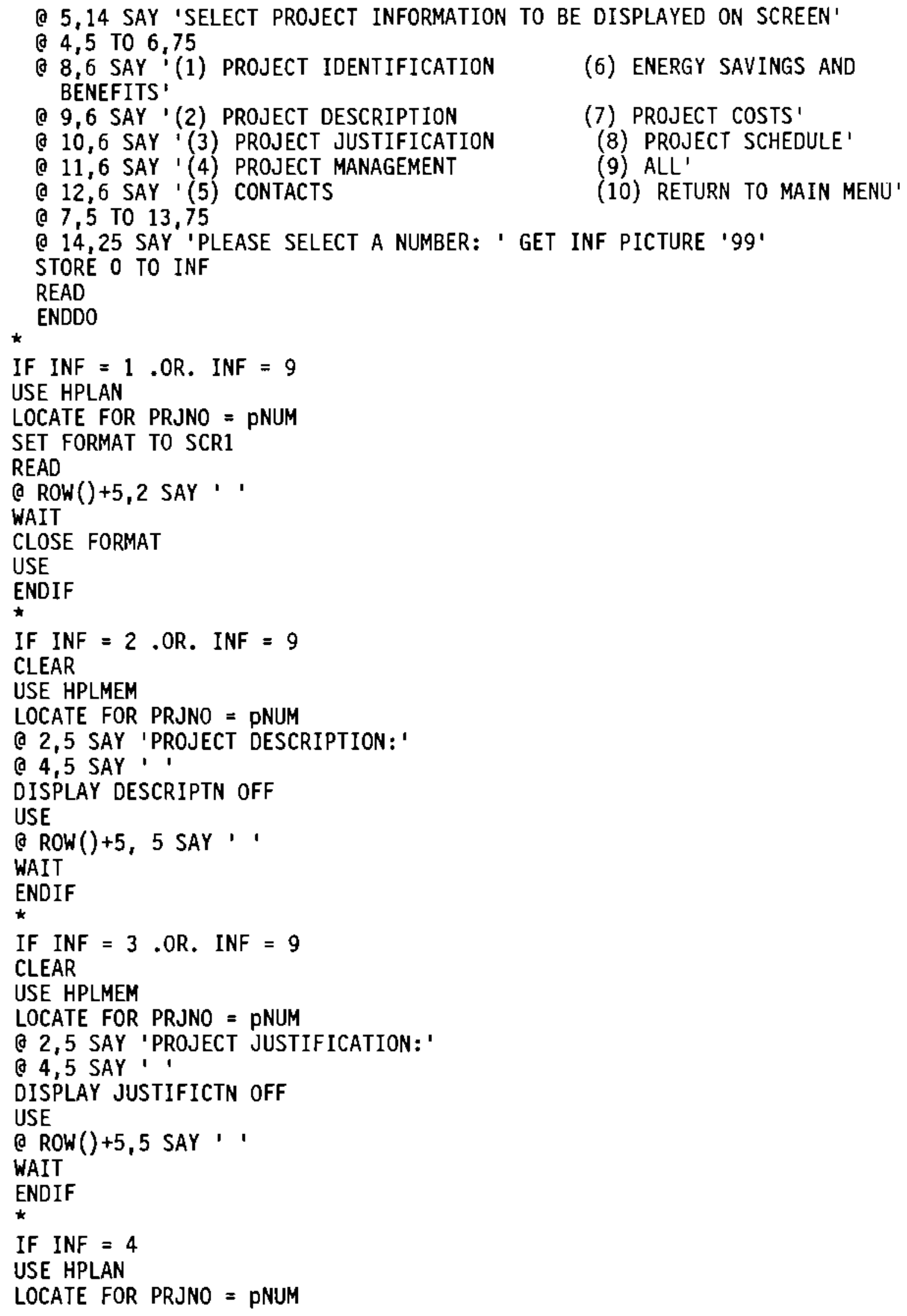

(7) PROJECT COSTS'

(8) PROJECT SCHEDULE'

(9) ALL'

(10) RETURN TO MAIN MENU' 


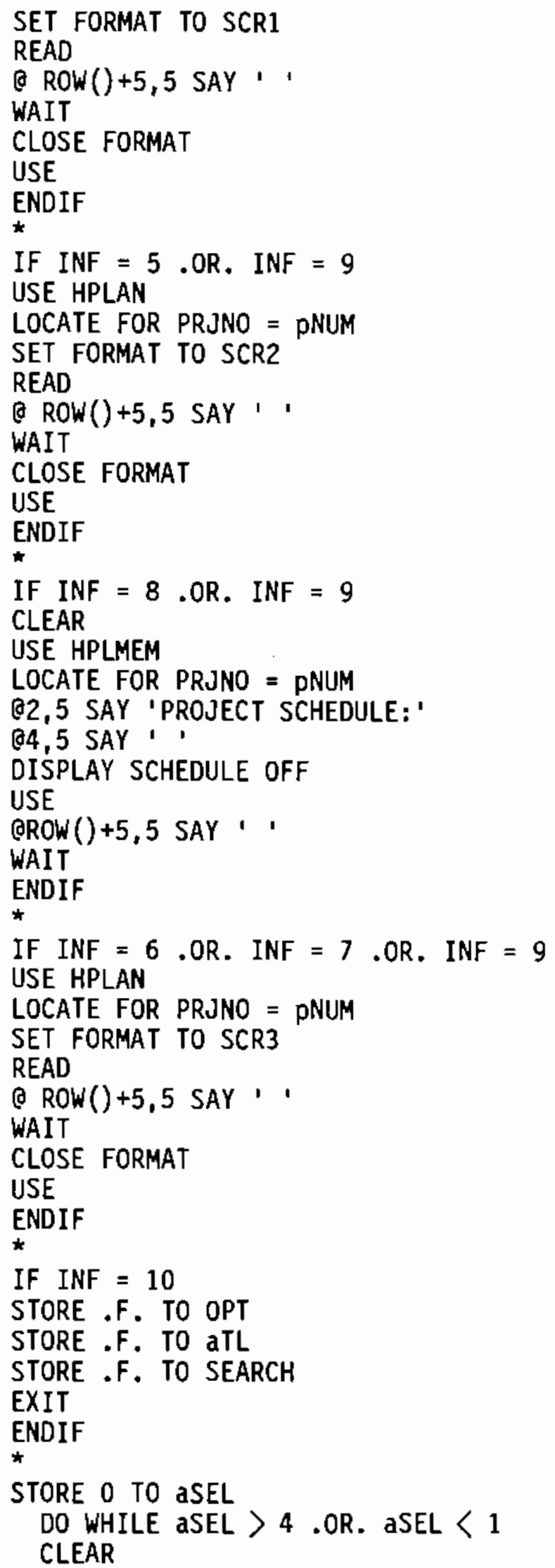




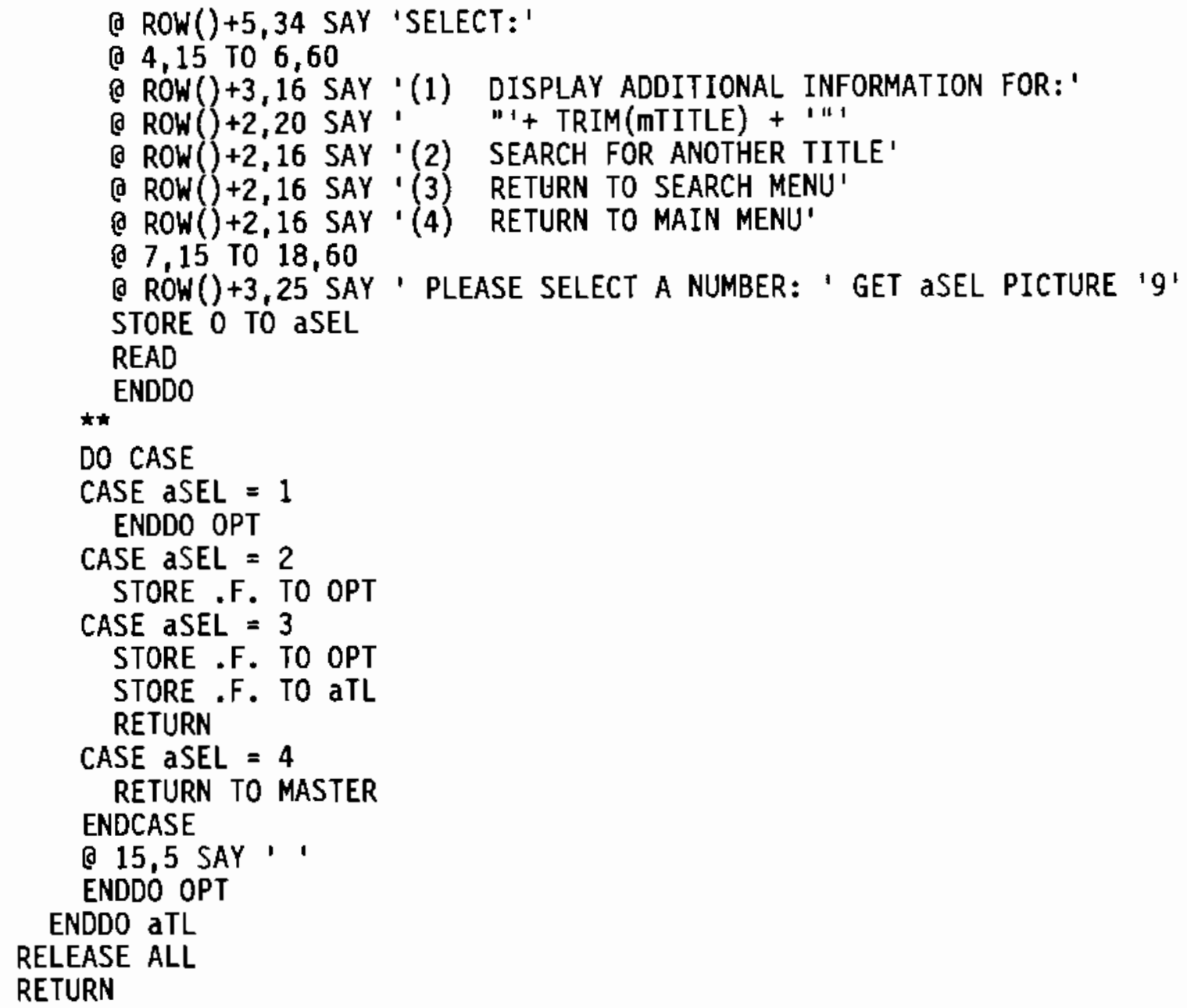




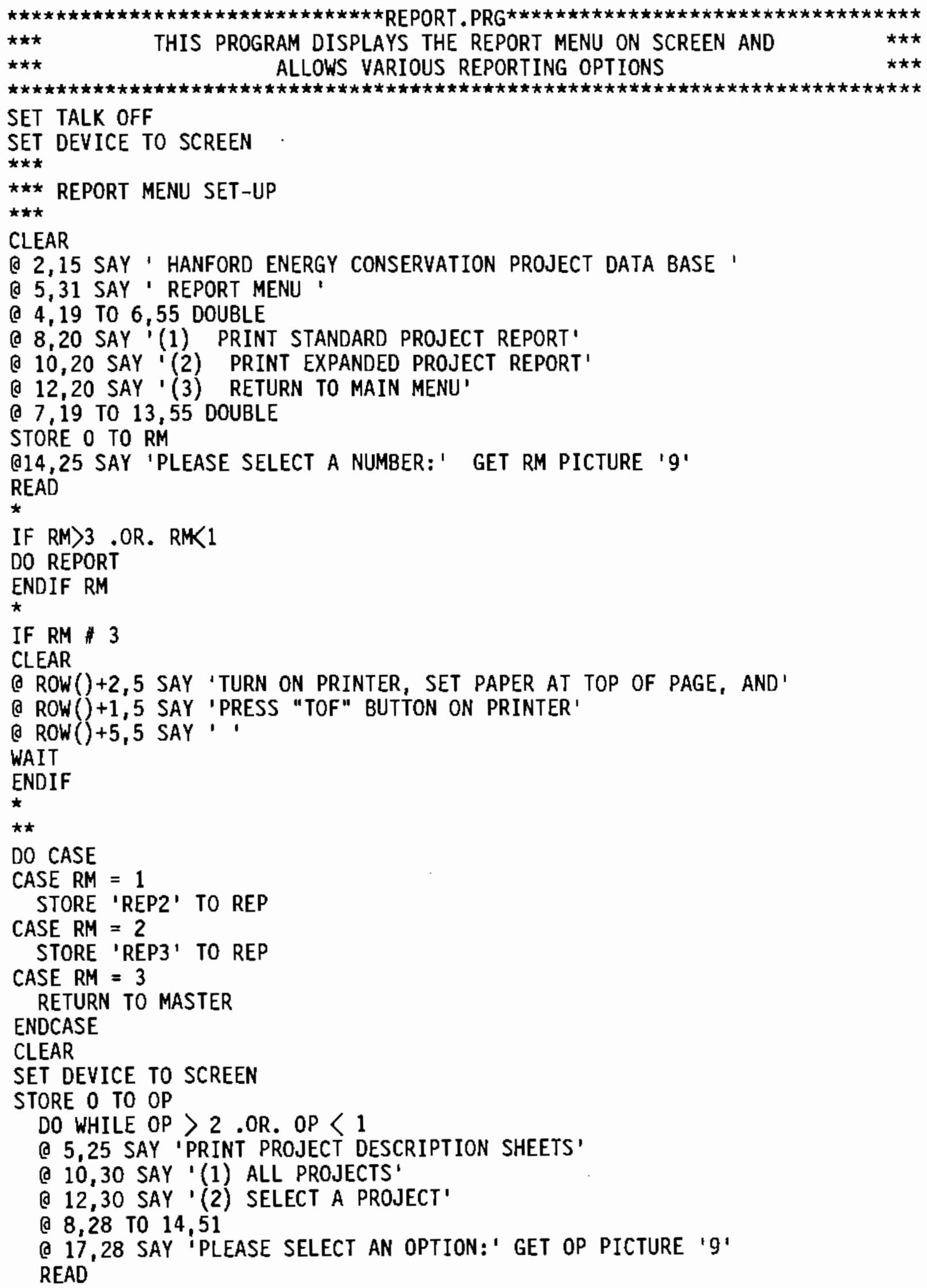




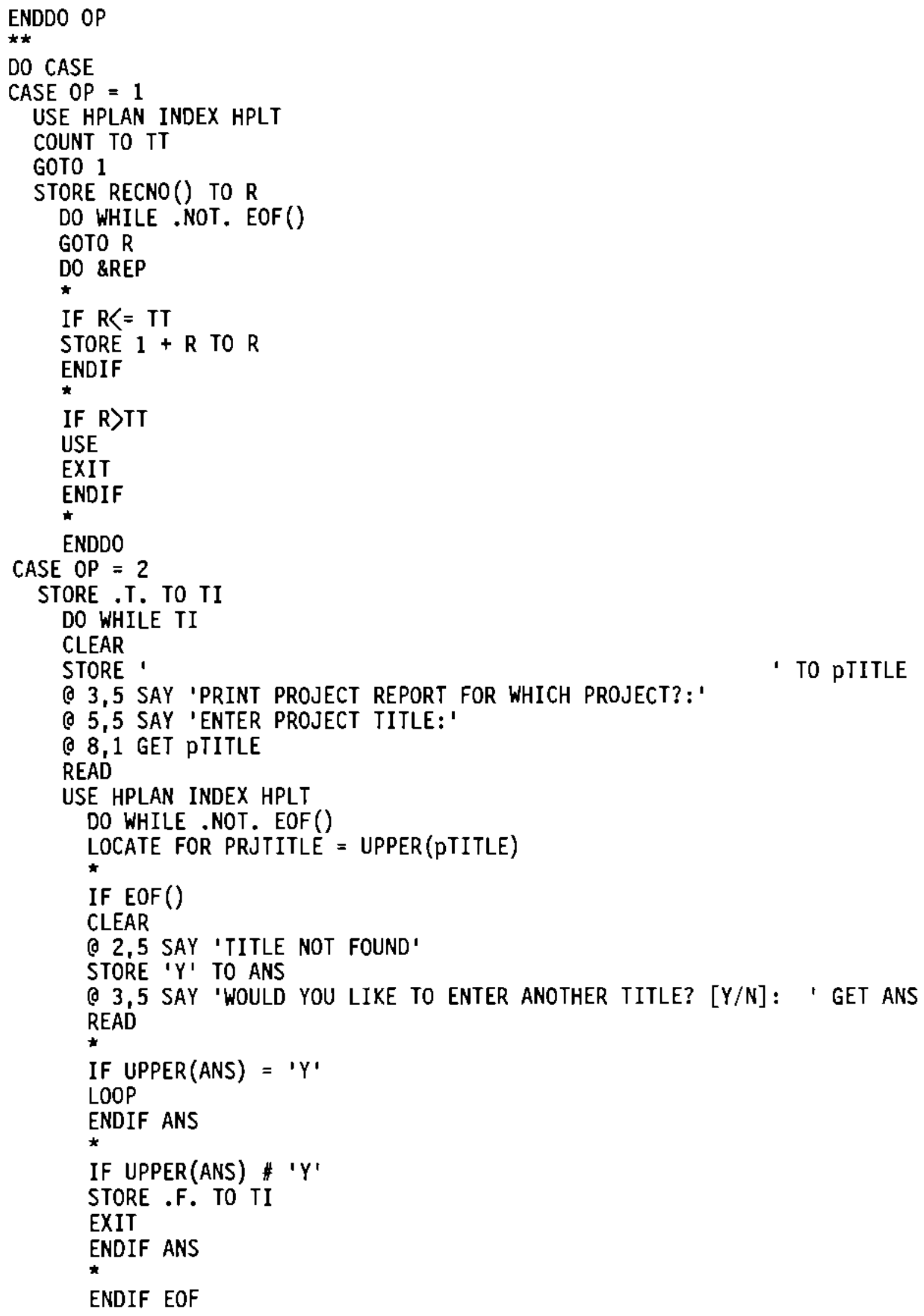




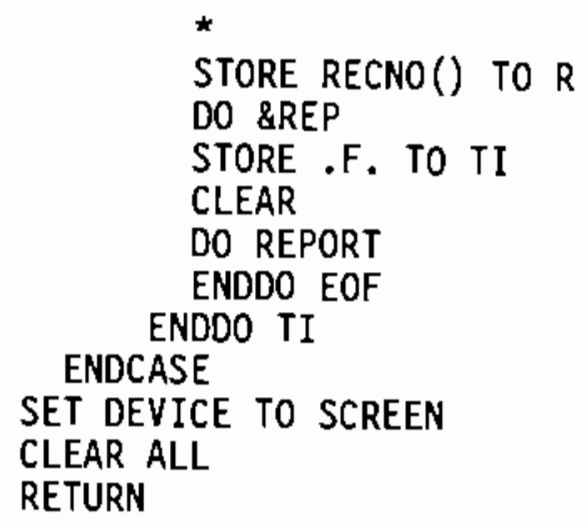




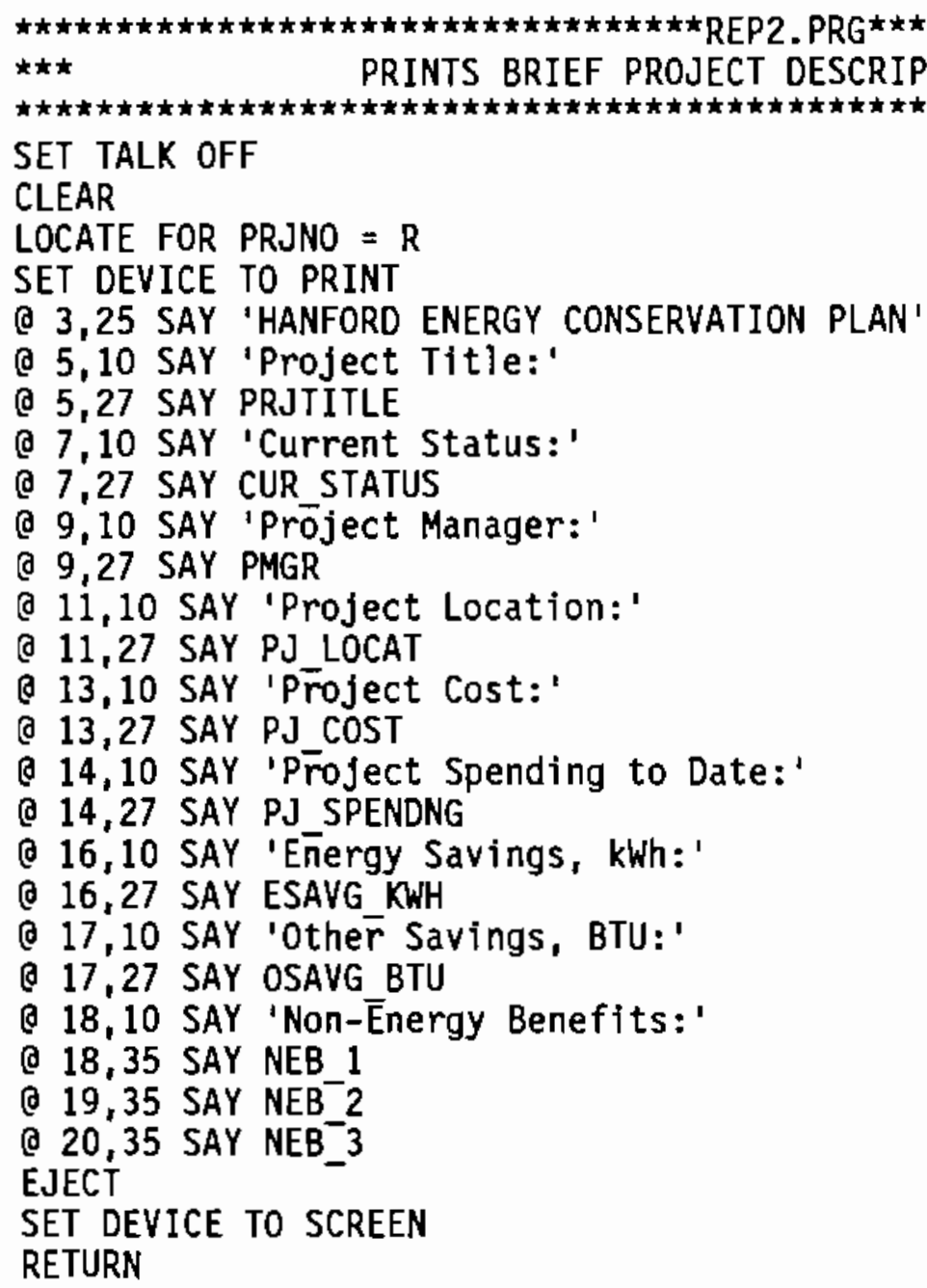




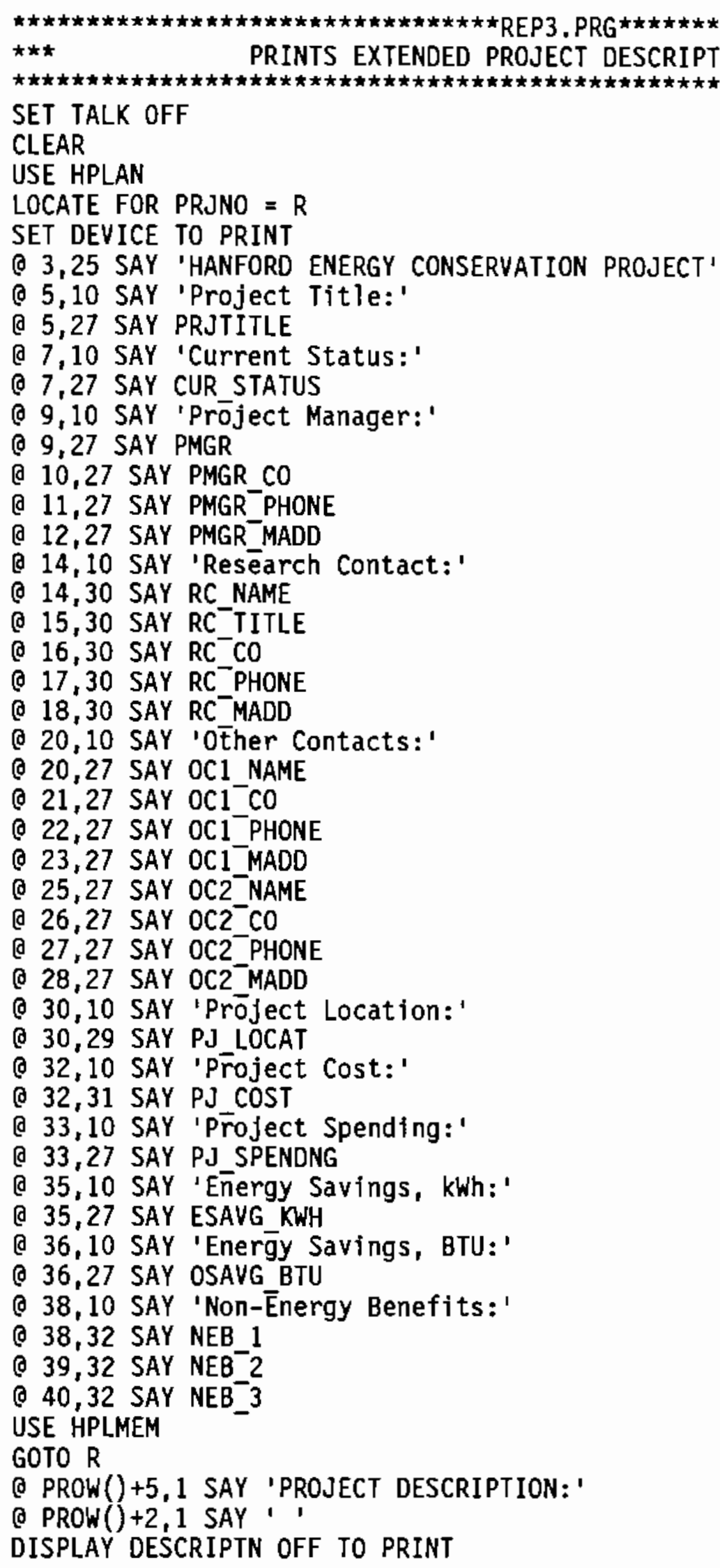




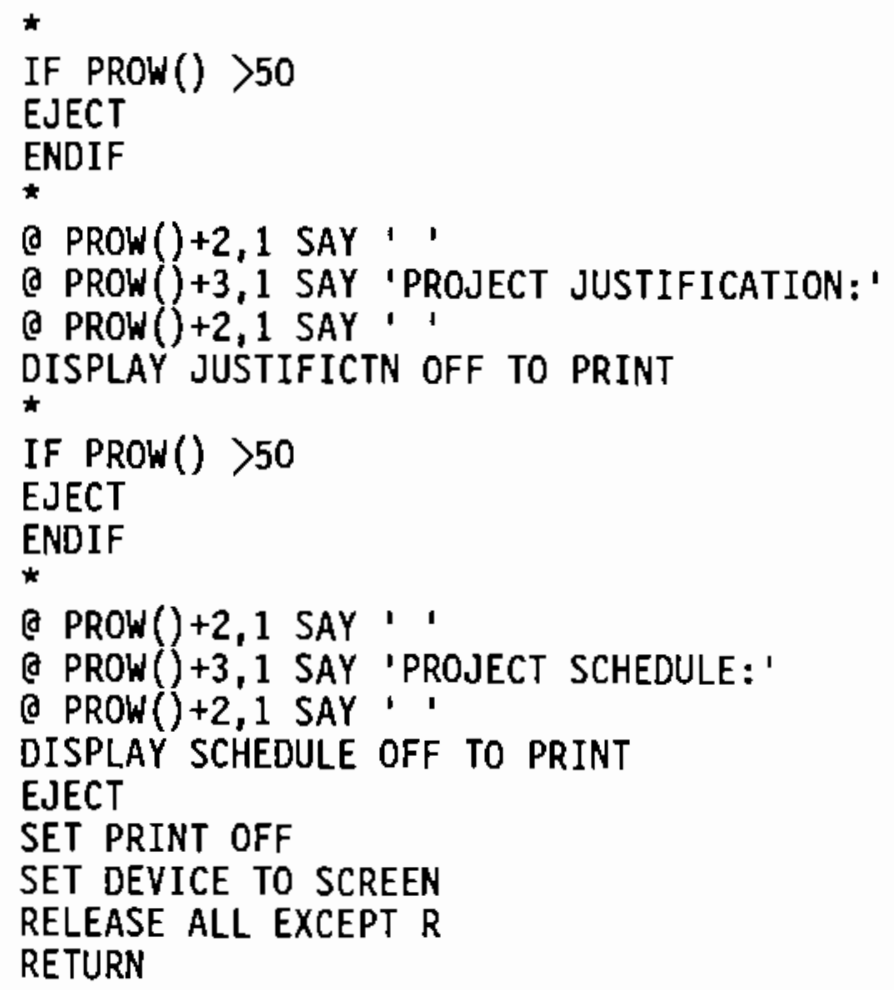




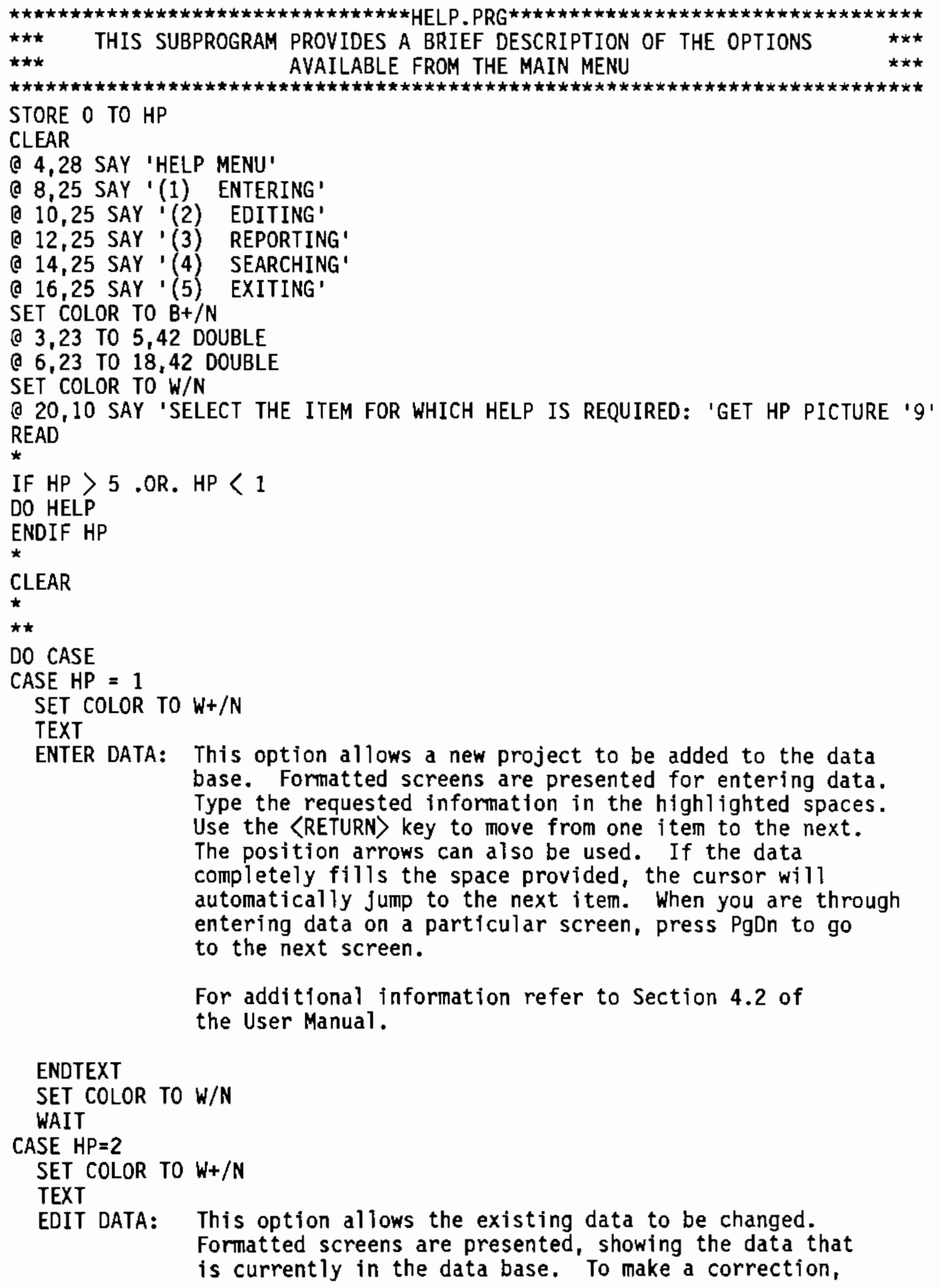

STORE 0 TO HP

CLEAR

(a 4,28 SAY 'HELP MENU'

(a 8,25 SAY '(1) ENTERING'

(d) 10,25 SAY ' (2) EDITING'

(d) 12,25 SAY '(3) REPORTING'

(d) 14,25 SAY '(4) SEARCHING'

(a 16,25 SAY '(5) EXITING'

SET COLOR TO $\mathrm{B}+/ \mathrm{N}$

a 3,23 TO 5,42 DOUBLE

a 6,23 TO 18,42 DOUBLE

SET COLOR TO W/N

a 20,10 SAY 'SELECT THE ITEM FOR WHICH HELP IS REQUIRED: 'GET HP PICTURE ' READ

*

IF HP $>5$.OR. HP $<1$

DO HELP

ENDIF HP

*

CLEAR

$\star$

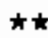

DO CASE

CASE HP $=1$

SET COLOR TO $W+/ \mathrm{N}$

TEXT

ENTER DATA: This option allows a new project to be added to the data base. Formatted screens are presented for entering data. Type the requested information in the highlighted spaces. Use the 〈RETURN> key to move from one item to the next. The position arrows can also be used. If the data completely fills the space provided, the cursor will automatically jump to the next item. When you are through entering data on a particular screen, press PgDn to go to the next screen.

For additional information refer to Section 4.2 of the User Manual.

\section{ENDTEXT}

SET COLOR TO W/N

WAIT

CASE HP $=2$

SET COLOR TO $\mathrm{W}+/ \mathrm{N}$

TEXT

EDIT DATA: This option allows the existing data to be changed.

Formatted screens are presented, showing the data that is currently in the data base. To make a correction, 
the new data is typed over the existing data. The user

has the option to edit all data, in which case each

formatted screen is displayed sequentially, or

to edit a given data set, in which case only the

pertinent screens are presented.

For additional information refer to Section 4.3 of

the User Manual.

\author{
ENDTEXT \\ SET COLOR TO W/N \\ WAIT \\ CASE HP $=3$
}

SET COLOR TO $\mathrm{W}+/ \mathrm{N}$

TEXT

PRINT REPORT: There are two reporting formats: (1) A brief project description sheet, and (2) an expanded project description sheet, The user can elect to print reports for all projects in the data base, or for a given project.

For additional information refer to Section 4.4 of the User Manual.

\title{
ENDTEXT \\ SET COLOR TO $W / N$ \\ WAIT \\ CASE HP $=4$ \\ SET COLOR TO $W+/ N$ \\ TEXT
}

SEARCH: This program option allows the user to search the data base for a given project title, for a combination of keywords, or for a combination of field constraints combined in a boolean expression. The title search program option allows the user to display all or selected information for that project on the screen. The keyword search and boolean search program options allow the user to display the titles of the projects that meet the specified conditions on the screen, print the titles, or print expanded description sheets for the projects.

For additonal information refer to Section 4.5 of the User Manua1.

\section{ENDTEXT}

SET COLOR TO $W / N$

WAIT

CASE HP $=5$

SET COLOR TO $W+/ N$

TEXT

EXIT: This option returns the user to the DOS operating system. For additional information refer to Section 4.7 of the User Manual. 


\section{ENDTEXT}

SET COLOR TO W/N

WAIT

ENDCASE

RETURN 
CLEAR

01,2 SAY '1. Project Title' GET PRJTITLE

03,2 SAY '2. Current Status' GET CUR_STATUS

05,2 SAY '3. Project Manager'

@6,2 SAY' A. Name:' GET PMGR

07,2 SAY ' B. Phone:' GET PMGR PHONE

[8,2 SAY ' C. Company:' GET PMMGR CO

09,2 SAY ' D. Mailing Address:' GET PMGR MADD

011,2 SAY '4. Research Contact'

012,2 SAY ' A. Name:' GET RC NAME

013,2 SAY' B. Title:' GET RC TITLE

014,2 SAY' C. Company:' GET $\bar{R} C$ CO

015,2 SAY ' D. Phone:' GET RC PHONE

016,2 SAY ' E. Mailing Address:' GET RC_MADD 


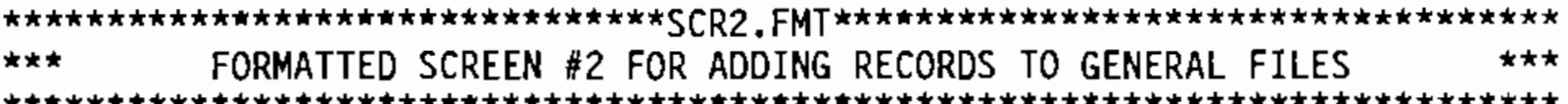

CLEAR

Q1,2 SAY 'PROJECT TITLE: '+ PRJTITLE

[03,2 SAY 'Contact in Operations and Construction'

20,2 SAY '5A. Name:' GET OC1 NAME

06,2 SAY '5B. Company:' GET OC1 CO

Q7,2 SAY '5C. Phone:' GET OC1 PḦONE

08,2 SAY 15D. Mailing Address: ${ }^{\top}$ GET OC1 MADD

011,2 SAY '6A. Name:' GET OC2 NAME

012,2 SAY '68. Company:' GET OC2 CO

013,2 SAY '6C. Phone:' GET OC2 PH̄ONE

014,2 SAY '6D. Mailing Address:' ${ }^{\top}$ GET OC2_MADD 


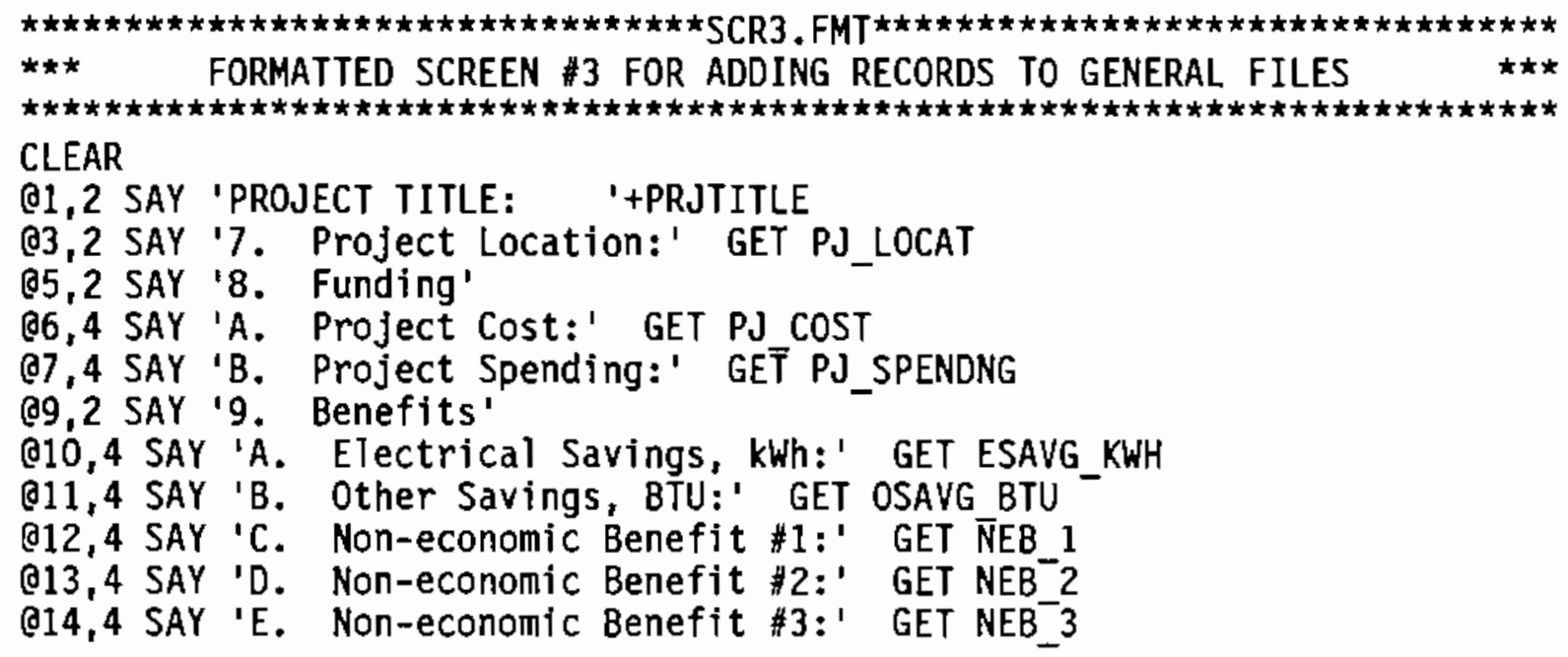




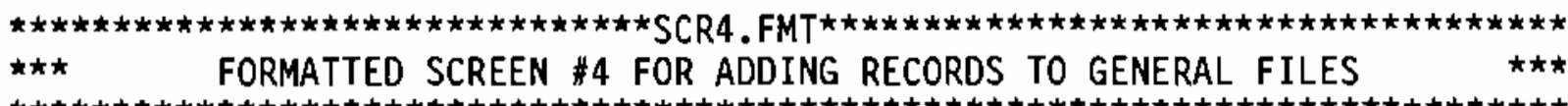

CLEAR

01,5 SAY 'Project Tit]e: ' tpTITLE

[3,10 SAY '10. TECHNICAL KEYWORDS'

05, 13 SAY 'A. AFFECTED AREA(S)'

[66, 15 SAY '1.' GET ARE1

[07,15 SAY '2.' GET ARE2

[8, 15 SAY ' 3. ' GET ARE3

[10,13 SAY 'B. CONTRACTOR(S) IN WORKING AREA'

011,15 SAY '1.' GET CON1

013,13 SAY ' $C$. FORM OF ENERGY SAVED'

014,15 SAY '1.' GET FOR1

015, 15 SAY '2.' GET FOR2

[17,13 SAY 'D. TYPE OF ENERGY SAVED'

[018,15 SAY '1.' GET TYPE1

[20,13 SAY 'E. OTHER'

021, 15 SAY ' 1. ' GET OTH1

222, 15 SAY '2.' GET OTH2

023,15 SAY '3.' GET OTH3 


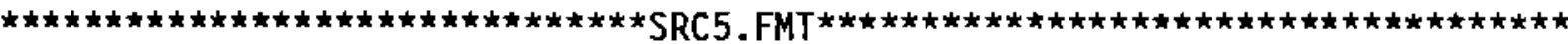

$\star \star \star$

FORMATTED SCREEN \#5 FOR ADDING RECORDS TO GENERAL FILES

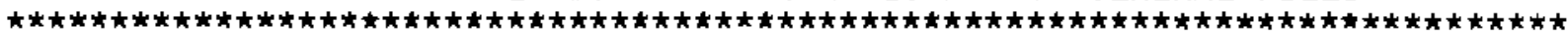

CLEAR

Q1,2 SAY 'PROJECT TITLE:

'+pTITLE

Q5,2 SAY 'Press 〈CtrlXPgDn> to edit the project description,'

06,2 SAY ' project Justification, or project schedule, '

07,2 SAY I place the cursor on the appropriate "memo" block'

08,2 SAY' using 〈RETURN>.'

010,2 SAY 'To save your changes, press 〈CtrlXPgup〉'

011,2 SAY ' 〈RETURN> takes you back'

013,2 SAY ' Project Description: ' GET DESCRIPTN

@15,2 SAY I Project Justification: ' GET JUSTIFICTN

017,2 SAY ' Project Schedule: ' GET SCHEDULE 
APPENDIX C

TROUBLE-SHOOTING GUIDE 
APPENDIX C

TROUBLE-SHOOTING GUIDE

This appendix provides instructions for recovering from certain abnormal events that may occur during the execution of the Hanford Energy Conservation Project Data Base. Included in this section are discussions of the following:

- Abnormal Termination

- Disk Full Message

- Loss of Data

\section{ABNORMAL TERMINATION}

The adaption of any newly developed computer code raises the possibility of abnormal termination during the execution of the code. In the event that this should occur during the execution of the Hanford Energy Conservation Project Data Base, a general message will be printed on the screen: indicating the type of problem that has occurred and the program and/or subprogram(s) in which the problem occurred, and (2) asking the user whether the command file should be terminated.

When the screen asks whether or not to terminate the command file, the following steps should be taken:

1. Type $Y$ to terminate the command file.

2. Type CLEAR ALL to close any open files.

3. Type DO MENU to restart the applications program.

4. If termination occurred during the data entry (ADD.PRG) or the data edit (EDIT.PRG) program, you should check the data base to see if the data you were entering before the termination has been stored. The edit program or the title search program can be used to display the project information on the screen for this check.

\section{DISK FULL MESSAGE}

Each time you add data to a data base or edit a data base, a backup file or the original data base is automatically made. The backup file has the same file name as the original file and the file extension .BAK. The storage of backup files will at times create a shortage of storage space on the disk (most likely to occur on a floppy disk). Data files should be backed up on 
separate disks as discussed in Section 4.7, rather than relying on these backup files. To prevent a disk full error message from occurring, the user can erase the backup files from the disk before entering the dBase III Plus program by typing the following after the DoS prompt:

$$
\text { ERASE *.BAK* This eliminates all backup files on the current drive. }
$$

If insufficient storage space is encountered during program execution, the following message will appear:

Disk ful1 when writing file - FILENAME

Abort, Ignore, or Delete old files (A, I or D)?

Abort

Selecting the abort (A) option causes the program to terminate its attempt to copy the file. The following message will appear:

**WARNING** Data will probably be lost confirm $(Y / N)$ ?

If you type $Y$, the data will be lost and the screen will display the dot prompt. Typing $\mathrm{N}$ will produce the disk full error message again.

Ignore

Selecting the ignore (I) option causes the program to reattempt to copy the file. Most likely this will be unsuccessful and the disk full error message will again be displayed.

Delete

Selecting the delete (D) option causes the program to sequentialiy display all of the files currently stored on the disk. The user is given the option of deleting each file as it appears on the screen in order to make more room on the disk. Files with file extension .BAK should be deleted first. After the entire list has been displayed, the program will automatically continue its attempt to copy the file. If sufficient space is still unavailable, the disk full error message will again appear. 
LOSS OF DATA

Loss of data from floppy or hard disk files can occur as a result of power surges or operator error. Surge-protection devices can be used to prevent the occurrence of the first type of data loss. The possibility of the latter occurring can be reduced by becoming familiar with the applications program and with dBase III. If inadvertent data loss occurs, the backup data base file can be copied to the master disk as follows:

IN DBASE III:

1. COPY FILE d1:FILENAME. EXT TO $\mathrm{d} 2:$ FILENAME.EXT, where $\mathrm{d} 1 \mathrm{and} \mathrm{d} 2$ are the source and destination drives, respectively.

2. The screen will state that the file already exists and will ask if you want to overwrite it. overwriting will delete the faulty information and store the data from the backup file onto the master disk.

IN DOS:

1. COPY $\mathrm{d} 1$ :FILENAME. EXT d2:FILENAME.EXT, where $\mathrm{d} 1$ and $\mathrm{d} 2$ are the source and destination drives, respectively.

2. The screen will state that one file has been copied. 
PNL-6318

UC -95

\section{DISTRIBUTION}

No. of

Copies

OFFSITE

5 DOE Technical Information Center

ONSITE

3 DOE Richland Operations office

D. R. Segna

J. J. Sutey

W. A. White

4 Westinghouse Hanford Company

R. L. Brown

W. R. Croxford

R. S. Poplin

R. W. Reed

2 Kaiser Engineering

J. A. Rathbone

L. H. Smith

26 Pacific Northwest Laboratory

L. L. Fassbender

J. D. Hughes

K. K. Humphreys (5)

C. H. Imhoff

T. J. Secrest

S. A. Weakley (10)

Technical Information Files (5)

Publishing Coordination (2) 
. - 